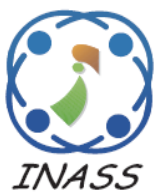

\title{
Indoor Positioning Systems Based on Li-Fi Technology Using RSS-Triangulation With Assisted by DNN
}

\author{
Kawther Dawood Salman ${ }^{1}$ \\ Ekhlas Kadhum Hamza ${ }^{1 *}$ \\ ${ }^{I}$ Department of Control and Systems Engineering, University of Technology, Baghdad, Iraq \\ * Corresponding author's Email: cse.19.02@grad.uotechnology.edu.iq
}

\begin{abstract}
Due to the rapid growth in mobile data traffic, academia and industry are considering Li-Fi (Light Fidelity) as an alternative to Wi-Fi (Wireless Fidelity). Li-Fi is a high-speed, two-way wireless network system that has several advantages over traditional radio frequency systems. To fully exploit the potential of $\mathrm{Li}$-Fi systems, users must be provided with a seamless connection, which must be achieved by carefully studying user mobility. Nowadays, most wireless Li-Fi network applications focus their design on solving some unspecific user-location problems that may fully achieve some preferred results in the domain they serve. For example, locating an unknown user in an indoor environment is considered a kind of solution for maintaining the QoS (Quality of Service) and delivering the signal to the user without distraction. Where the main research problem lies in the signal interference, loss, and scattering in the Li-Fi network, it is a big problem because it reduces the network performance and coverage. Therefore, to solve this problem, this research investigates the locating of the mobile user within the Li-Fi equipped room to obtain the best possible coverage of the user's service. The aim of the research was divided into two stages. In the first stage, the method used in our work was presented by showing the triangulation method in simulating user location data (sensor simulation), the first stage was not affected by noise, as it serves as proof of the correctness of our work and depends in the second stage when it is under the influence the noise. In the second stage, the method of RSS - triangulation (Receiving Signal Strength - Triangulation) was adopted to simulate the user's location data (a simulation of the sensor) and under the influence of noise and implemented on a deep learning algorithm to determine the accuracy of the user's location and how to deal with noise. In the simulation results for the data in the first stage, our work was validated using the triangulation method in data simulation. The average error for the X-Axis was $2.17344 \times 10^{-14} \mathrm{~cm}$; Y-Axis was $6.44762 \times 10^{-14} \mathrm{~cm}$ and Z-Axis $4.65690 \times 10^{-11} \mathrm{~cm}$ the results obtained from the triangulation simulation were close to the real results. In the second stage, when adopting the RSS-Triangulation method under effect the noise, the average error was achieved on the X-axis $2.05612 \times 10^{-3} \mathrm{~cm}$, Y-Axis was $4.56249 \times 10^{-3} \mathrm{~cm}$, and Z-Axis $5.10474 \times 10^{-3} \mathrm{~cm}$ where The DNN (Deep Neural Network) showed how to deal with noise, the highest error was obtained on the $\mathrm{X}$-axis $2.51535 \mathrm{~cm}$, the $\mathrm{Y}$-axis $2.25903 \mathrm{~cm}$, and the $\mathrm{Z}$-axis $4.22898 \mathrm{~cm}$ for an indoor environment of $5 \mathrm{~m} \times 5 \mathrm{~m} \times 3 \mathrm{~m}$
\end{abstract}

Keywords: Li-Fi, VLC, RSS, Triangulation, VLP, DNN.

\section{Introduction}

The growing demand for wireless data, which is expected to reach 49 exabytes by 2022 , is motivating academia and the industry to invest in alternative technologies. These include millimeter wave (mmWave), MIMO (massive multiple input multiple output), free-space optical communication, and Light-Fidelity to support the growth of data traffic and the next generation of high-speed wireless communication systems. Among these technologies, $\mathrm{Li}-\mathrm{Fi}$ is a novel bi-directional, high speed, and fully networked wireless communication technology that was first proposed and used by Professor Harald Haas of the university of Edinburgh, UK. This was done at the TED world conference in 2011. Li-Fi technology was awarded the place of "One of the 50 best inventions of 2011" on TED's global website [1]. Where this technique demonstrated its use of vision light as a propagation medium in the downlink for illumination and communication purposes. It may use 
infrared in the uplink so that the lighting in the room remains unaffected, and also avoid interference with visible light in the downlink [2, 3]. Li-Fi offers significant advantages over RF (radio frequency) systems as radio frequencies rise, the complexity increases, and radio frequency interference becomes a major problem. Where Li-Fi has overcome these problems, as the frequency range available in the visible light spectrum is very large between $400 \mathrm{~Hz}$ to $800 \mathrm{~Hz}$ (more than 103 times greater than the entire

RF spectrum) it has been observed that can achieve a data transfer rate of up to 100 Gbit in second, a highly energy-efficient, fairly direct diffusion that uses LED (light-emitting diodes) as transmitters and PD (photodiode) as receivers. The transmitter and receiver terminate respectively, and it enhances security because the light is not transmitted through opaque objects [4, 5]. Moreover, $\mathrm{Li}-\mathrm{Fi}$ can be used in any RF restricted area such as hospitals and aircraft cabins.

To realize the full potential of Li-Fi cellular networks, many aspects of $\mathrm{Li}-\mathrm{Fi}$ still need to be carefully studied.

The Li-Fi channel is relatively deterministic, which permits a potential improvement of the bidirectional user throughput by reducing the amount of feedback. This is more pivotal in multiuser scenarios where the AP (access point) requires CSI (channel state information) from all users to efficiently allocate the available resources to the users.

Where random device location is an important factor that can affect the received SNR (signal to noise ratio) and as a result the throughput remarkably in the Li-Fi network [6, 7]. The Li-Fi is a promising technology that is expected to be a part of the future 5th generation to fulfill its high data rate requirements and $\mathrm{Li}-\mathrm{Fi}$ as a fully networked subset of OWCs (optical wireless communication) must be able to support seamless connectivity for mobile users.

To analyze random device location on channel gain and received SNR, data simulation based on received signal strength- triangulation and input this data to the deep learning algorithm to localize the device and display its statistics has been proposed in this work. However, due to the small cell radius of Li-Fi networks, which is on the order of a few meters, and compared to the average walking speed of a human, $\mathrm{v}=1 \mathrm{~m} / \mathrm{s}$, a mobile user may remain in a LiFi cell only for a few seconds (The speed of light is $299,792,458$ meters per second). In this research, to take full advantage of the potential of Li-Fi cellular networks in user locating, the relevant recent work shown in table 1 has been studied, the above aspects and challenges are discussed and effective solutions provided.

The other parts in the presented work are: section 2 is presented the $\mathrm{Li}-\mathrm{Fi}$ evaluation of indoor localization systems, while section 3 shows three-dimensional positioning algorithm based on DNN. Section 4 describes the methodology of the Li-Fi simulation model, while Section 5 shows the simulation results and analysis of this study and section 6 presented a comparison and discussion between our work and recent researches. Finally, conclusions and Future Work in Section 7.

\section{Li-Fi evaluation of indoor localization systems}

Positioning is an essential tool for providing location-based services such as navigation and creating maps and tracking objects, etc. As the mainstream positioning technology at present, the GPS (global positioning system) is a satellite-based radionavigation system that provides geolocation to a GPS receiver anywhere on earth $[18,19]$. However, because transmitted signals are degraded and interrupted by obstacles, such as ceilings and walls, GPS becomes less accurate in indoor scenarios [20]. Instead, positioning principles were used, and an IPS (intrusion prevention system) based on short-range wireless communication technologies such as $\mathrm{Li}-\mathrm{Fi}$, Wi-Fi, and bluetooth was developed [21]. But in this research, the work was conducted in an indoor environment based on Li-Fi technology with the characteristics of this technology for its use of LED infrastructures and does not affect human health In the following sub-sections, surveys were presented position estimated and position principles to summarize Li-Fi-based positioning technologies [22].

\subsection{Position estimation}

In this section, a brief introduction on the development and classification of IPS techniques (especially those based on $\mathrm{Li}-\mathrm{Fi}$ ) where position estimation consists of estimating the reference node position coordinates using physical measurements, for example, TOA (time of arrival), TDOA (time differential of arrival), AOA (angle of arrival), or RSS. In general, the mathematical method and the required information can be used to classify IPS approaches. There are three types of mathematical methods used for IPS in the current literature: fingerprinting, triangulation, and proximity as shown in Fig. 1 [22]. 
Table 1. Summary of the state of the artworks of indoor Li-Fi

\begin{tabular}{|c|c|c|c|c|c|c|c|}
\hline Ref. & Year & $\begin{array}{l}\text { Signal } \\
\text { Properties }\end{array}$ & $\begin{array}{l}\text { Intrusion } \\
\text { Prevention } \\
\text { System type }\end{array}$ & $\begin{array}{l}\text { Positioning } \\
\text { Algorithm }\end{array}$ & $\begin{array}{l}\text { Average } \\
\text { Distance } \\
\text { error }\end{array}$ & $\begin{array}{l}\text { Average } \\
\text { Positioning } \\
\text { Time }\end{array}$ & $\begin{array}{l}\text { Position } \\
\text { Error }\end{array}$ \\
\hline [8] & 2017 & RSS & $\longrightarrow$ & $\begin{array}{l}\text { PSO ( Particle } \\
\text { Swarm } \\
\text { Optimization) }\end{array}$ & $3.9 \mathrm{~mm}$ & & $2.96 \mathrm{~mm}$ \\
\hline [9] & 2017 & $\begin{array}{l}\text { AOA and } \\
\text { TDOA }\end{array}$ & Triangulation & \begin{tabular}{l}
\multicolumn{1}{c}{ MEX and } \\
LSM Method \\
of Exhaustion \\
and Least \\
Squares \\
Method)
\end{tabular} & $\begin{array}{c}\text { MEX: } \\
3: 20 \mathrm{~cm} \\
\text { LSM: 14:66 } \\
\mathrm{cm}\end{array}$ & $\begin{array}{l}\text { MEX: 0:36 } \\
\quad \text { sec } \\
\text { LSM: 0:001 } \\
\text { sec. }\end{array}$ & $17 \mathrm{~cm}$ \\
\hline [10] & 2018 & RSS & Trilateration & $\begin{array}{l}\text { Genetic } \\
\text { Algorithm }\end{array}$ & $2.32 \mathrm{~cm}$. & & $5 \mathrm{~cm}$ \\
\hline [11] & 2018 & RSS & Fingerprinting & $\begin{array}{l}\text { Neural } \\
\text { Networks }\end{array}$ & $0.4 \mathrm{~mm}$. & & $2 \mathrm{~m}$ \\
\hline [12] & 2019 & RSS & Fingerprinting & $\begin{array}{l}\text { K-Means } \\
\text { Clustering }\end{array}$ & $\longrightarrow$ & & $40 \mathrm{~cm}$ \\
\hline [13] & 2019 & $\begin{array}{l}\text { RSS and } \\
\text { PDOA }\end{array}$ & Triangulation & $\begin{array}{l}\text { ANN } \\
\text { (Artificial } \\
\text { Neural } \\
\text { Networks) }\end{array}$ & & & $12 \mathrm{~cm}$ \\
\hline [14] & 2019 & RSS & Fingerprinting & $\begin{array}{l}\text { ELM } \\
\text { (Extreme } \\
\text { Learning } \\
\text { Machine) }\end{array}$ & & $0.469 \mathrm{~s}$ & $0.08 \mathrm{~m}$ \\
\hline [15] & 2019 & RSS & Triangulation & $\begin{array}{l}\text { DNN (Deep } \\
\text { Neural } \\
\text { Network) }\end{array}$ & & & $11.93 \mathrm{~cm}$ \\
\hline [16] & 2020 & RSS & - & $\begin{array}{l}\text { IHBA } \\
\text { (Improved } \\
\text { Hybrid Bat } \\
\text { Algorithm) }\end{array}$ & & $0.89 \mathrm{~s}$ & $3.64 \mathrm{~cm}$ \\
\hline [17] & 2021 & RSS & Fingerprinting & $\begin{array}{l}\text { DNN (Deep } \\
\text { Neural } \\
\text { Network) }\end{array}$ & & $18 \mathrm{~ms}$ & $14.55 \mathrm{~cm}$ \\
\hline
\end{tabular}

The most popular method is triangulation, which uses the geometric properties of triangles to measure the distance or angle between the device and fixed known points (named beacons). Triangulation is usually the most accurate, but it is also the most difficult in terms of facility and computation. A 2D (tow dimensional) location measurement requires at least three APs with a single receiver, and a 3D location measurement requires four APs (three dimensional).

The simplest positioning method is proximity, in which a mobile device's location is linked to the coverage range of nearby APs. If multiple APs recognize the device, the location can be estimated based on the overlapping coverage areas of those APs.
As a result, if the overlapping area is large, this method has a low level of accuracy.

In comparison, fingerprint can provide accuracy by using location-dependent information, but it does so at the expense of an offline radio map [23, 24]. And focused our explanation on the method used is triangulation, as it is the most used for the indoor LiFi environment and most accurate.

\subsubsection{Proximity}

Only if the user is close to the corresponding point can a proximity indoor positioning system provide relative location information. When a user is 


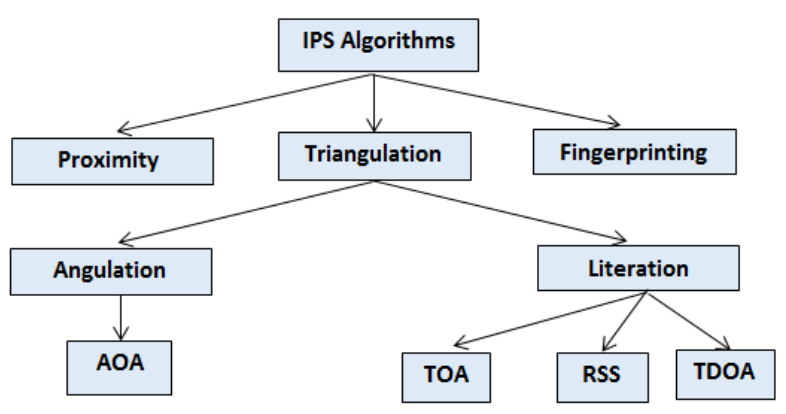

Figure. 1 Categories of IPS techniques

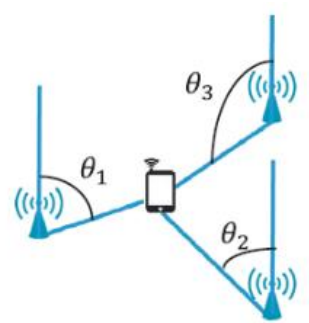

Figure. 2 Angulation method

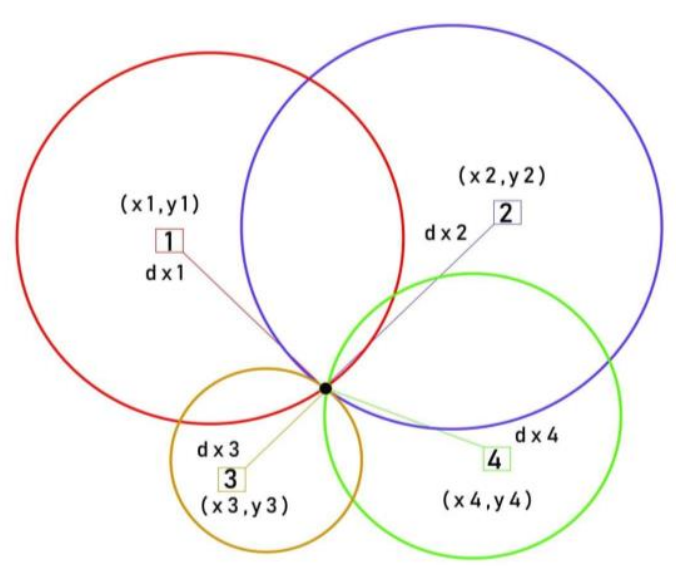

Figure. 3 Literation method

in close proximity to an object or a product that is associated with a receiver, the user's location can be determined as being in that receiver's vicinity. when the user is detected from more than one receiver, the user may be attached to the receiver with the strongest signal. But, when the overlapping area is large, the proximity method has poor accuracy and does not produce valid results [25].

\subsubsection{Fingerprinting}

Fingerprinting algorithms are usually accomplished in two steps: the goal of the training step is to create a fingerprint database, while the goal of the positioning step is to estimate location by comparing current measured signal strengths to the database. The database is built by selecting reference points and measuring the signal strengths of all access points for each reference point. The characteristics of each reference point are then determined and stored in the database in this manner. The target measures the signal strengths of all access points during the positioning step, and the measurements are compared to the data stored in the database using a matching algorithm. As a result, the target's location will be estimated. A deterministic or probabilistic approach can be used in the matching algorithm. In the deterministic approach, the user's coordinates are estimated using the smallest distance between the online measured fingerprint and all offline fingerprints, and the average signal strength measurements for each access point at each reference point are stored in the database. The K-nearest neighbor algorithm is a deterministic location determination method based solely on K-nearest offline fingerprints. The deterministic approach is not very accurate due to the large variation in signal strengths. As the number of reference points and measurements increases, fingerprinting performance improves. As the number of reference points grows, the granularity grows as well. In contrast, fingerprinting training is a time-consuming task that is difficult to complete in a crowded indoor environment [26].

\subsubsection{Triangulation}

In the same way that GPS is used for outdoor environments, the geometric properties of triangles can be used for indoor localization. The target's location can be determined by computing angles for several reference points. Angulation is the name for this type of triangulation. Literation is another method of triangulation. The target's location is estimated in literation based on distances measured to several reference points. The concepts of angulation and literation types are explained in detail in the following points from this subparagraph [27].

\subsubsection{Angulation}

The angle of arrival (AOA) is used in angulation algorithms. As shown in Fig. 2, this algorithm can locate a target at the intersection of the angle direction lines. AOA requires a directional antenna or an antenna array to compute the angles. Unlike some of the literation algorithms described in the following subsection, time synchronization between the reference points is not required. The major disadvantages of angulation algorithms are their complex hardware requirements and their sensitivity to a variety of factors [27].

\subsubsection{Literation}

Literation algorithms can locate the target by 
exploiting triangulation equations to calculate the distance between the LED and many user points as shown in Fig. 3. Then the distances extracted from the Literation method are used within the method of measuring RSS values at the target and determining its location [27, 28].

A Literation equation is non-linear, which is why the intersection of several circular lines in one geometrical approach isn't simple. In Three Dimensional space, 3 LEDs or more are needed for the estimation of the point of intersection $[29,30]$.

To deal with that problem, an approach of estimation is necessary. The RSS performs the calculation of the distance between the user and the LED, Assuming that $\mathrm{x} 1, \mathrm{y} 1 \& \mathrm{z} 1$ are the LED1 coordinates, $\mathrm{Yi}$ and $\mathrm{xi}(\mathrm{i}=1$ 4) represent the other coordinates of the LED, and $\mathrm{x}, \mathrm{y}$, and $\mathrm{z}$ are representing the actual coordinates of the mobile station. Then, the euclidian distance from the mobile station and each one of the LEDs has been represented by $\mathrm{dxy}_{1}^{2}$ in below equation [29].

$$
\begin{gathered}
d_{x y_{1}^{2}}=\left(x-x_{1}\right)^{2}+\left(y-y_{1}\right)^{2}+ \\
\left(z-z_{1}\right)^{2} \\
d_{x y_{2}^{2}}=\left(x-x_{2}\right)^{2}+\left(y-y_{2}\right)^{2}+ \\
\left(z-z_{2}\right)^{2} \\
d_{x y_{3}^{2}}=(2) \\
+\left(z-x_{3}\right)^{2}+\left(y-y_{3}\right)^{2} \\
+(z) \\
d_{x y_{4}^{2}}=\left(x-x_{4}\right)^{2}+\left(y-y_{4}\right)^{2} \\
+\left(z-z_{4}\right)^{2}
\end{gathered}
$$

In equations above $\mathrm{d}_{x y_{i}^{2}}$ for $\mathrm{i}=1, \ldots \ldots, 4$ denotes the number of LEDs. The error due to the time delay is the lowest in $x_{1}^{2}$, we can use Eq. (1) to the maximum extent to reduce the loss due to the time delay in positioning in general. This is only possible because we have 4 equations and 3 unknowns (x, y, and $\mathrm{z}$ ). Thus using equation subtraction, we can get 3 equations with groups as Eq. (1, 3), Eq. (2, 3), Eq. (1, 4) [27]. By applying this technique, we obtain 3 equations which can be appropriately stated in matrix form as follows:

$$
\begin{gathered}
{\left[\begin{array}{ccc}
\left(-x_{1}+x_{3}\right) & \left(-y_{1}+y_{3}\right) & \left(-z_{1}+z_{3}\right) \\
\left(-x_{2}+x_{3}\right) & \left(-y_{2}+y_{3}\right) & \left(-z_{2}+z_{3}\right) \\
\left(-x_{1}+x_{4}\right) & \left(-y_{1}+y_{4}\right) & \left(-z_{1}+z_{4}\right)
\end{array}\right]\left[\begin{array}{l}
x \\
y \\
z
\end{array}\right]} \\
=\frac{1}{2} \times
\end{gathered}
$$

$$
\left[\begin{array}{ccc}
\left(-x_{1}^{2}+x_{3}^{2}\right) & \left(-y_{1}^{2}+y_{3}^{2}\right) & \left(-z_{1}^{2}+z_{3}^{2}\right) \\
\left(-x_{2}^{2}+x_{3}^{2}\right) & \left(-y_{2}^{2}+y_{3}^{2}\right) & \left(-z_{2}^{2}+z_{3}^{2}\right) \\
\left(-x_{1}^{2}+x_{4}^{2}\right) & \left(-y_{1}^{2}+y_{4}^{2}\right) & \left(-z_{1}^{2}+z_{4}^{2}\right) \\
\times \\
\left(-d_{x y_{1}^{2}}+d_{x y_{3}^{2}}\right) \\
\left(-d_{x y_{2}^{2}}+d_{x y_{3}^{2}}\right) \\
\left(-d_{x y_{1}^{2}}+d_{x y_{4}^{2}}\right)
\end{array}\right]
$$

For getting the coordinates $(\mathrm{x}, \mathrm{y}$, and $\mathrm{z})$, the following can be useful:

$$
\begin{aligned}
& \underbrace{\left[\begin{array}{l}
x \\
y \\
z
\end{array}\right]}_{V}=\frac{1}{2} \times \\
& \underbrace{\left[\begin{array}{lll}
\left(-x_{1}+x_{3}\right) & \left(-y_{1}+y_{3}\right) & \left(-z_{1}+z_{3}\right) \\
\left(-x_{2}+x_{3}\right) & \left(-y_{2}+y_{3}\right) & \left(-z_{2}+z_{3}\right) \\
\left(-x_{1}+x_{4}\right) & \left(-y_{1}+y_{4}\right) & \left(-z_{1}+z_{4}\right)
\end{array}\right]^{-1} \times}_{A} \\
& \underbrace{\left[\begin{array}{ccc}
\left(-x_{1}^{2}+x_{3}^{2}\right) & \left(-y_{1}^{2}+y_{3}^{2}\right) & \left(-z_{1}^{2}+z_{3}^{2}\right) \\
\left(-x_{2}^{2}+x_{3}^{2}\right) & \left(-y_{2}^{2}+y_{3}^{2}\right) & \left(-z_{2}^{2}+z_{3}^{2}\right) \\
\left(-x_{1}^{2}+x_{4}^{2}\right) & \left(-y_{1}^{2}+y_{4}^{2}\right) & \left(-z_{1}^{2}+z_{4}^{2}\right) \\
\times & \\
\cdot & \\
\left(-d_{x y_{1}^{2}}+d_{x y_{3}^{2}}\right) \\
\left(-d_{x y_{2}^{2}}+d_{\left.x y_{3}^{2}\right)}\right. \\
\left(-d_{x y_{1}^{2}}+d_{x y_{4}^{2}}\right)
\end{array}\right]}_{B}
\end{aligned}
$$

This equation can be renamed as:

$$
V=\frac{1}{2} \times A^{-1} \times B
$$

Through the derivations for the triangulation equation, the coordinate of the user's location can be found by Eq. (7).

\subsection{Positioning principles}

\subsubsection{Angle of arrival}

The angle of arrival (AOA) principle calculates the angle $\varphi$ of a visible light arrives to reference node. The direction of arrival is dependent on the LED distance. AOA antennas are made of an array of receptor elements to calculate the visible light angle of arrival by measuring the phase difference at each element of the array. 
Using the AOA method has a few drawbacks. The accuracy of location estimation decreases as the distance between the target node and the transceiver stations grows because of the propagation characteristics of the received signal change. To use the AOA method, the network must use directional antennas to determine the angle of arrival, and directional antennas increase the wireless system's costs [31].

\subsubsection{Time of arrival and time difference of arrival methods}

The signal propagation time from transmitter to receiver is used in the time of arrival (TOA) and time difference of arrival (TDOA) methods. The TOA method estimates the distance between the reference node and transmitter and determines the one-way propagation time. The target and reference nodes' clocks must be precisely synchronized for this method to work. When multiple signals are generated from several reference nodes and arrive at a receiver device, the TDOA method processes the time difference between them. The receiver device can then calculate its position. According to each TDOA, the receiver device should be on a hyperbolic with constant range differences between the two transmitting reference nodes. In $2 \mathrm{D}$, finding the position location of a receiver device requires two pairs of reference nodes, while in 3D, three pairs of reference nodes are required. Because these methods rely entirely on accurate time measurements, any inaccuracy in time measurement will result in range estimation errors [32].

There are drawbacks to both of these methods that should be considered. Weak time synchronization is a major source of error in these methods, and multipath propagation is another source of error. Because changing the time of arrival of the signal to the receiver causes large errors in positioning location measurements, low SNR reduces the resolution of TOA and TDOA measurements, which has an impact on measurement accuracy [33].

\subsubsection{Received signal strength}

Received signal strength (RSS) is based on the fact that the received visible light signal power is inversely proportional to the distance. Visible light signals are attenuated as the distance between the reference node and transmitter increases. Where the power of the received visible light signal by the receiver's circuit and is expressed in $\mathrm{dB} \mathrm{m}$ units. Some localization methods based on RSS used an optical propagation model to calculate the distance between the reference node and transmitter [34].

The benefit of RSS includes [35]: The RSS method can provide high accuracy in short-range and LOS environments, and it can be used in systems without requiring new hardware to be installed in both the network and target nodes. So the RSS is still easier and less expensive than other methods, which necessitate the installation of new hardware in various system nodes and it has another significant advantage in that it does not necessitate time synchronization between system nodes.

To measure RSS Measurement model for Li-Fi, the channel DC gain in Li-Fi systems is proportional to the radiant intensity and the effective light collection is as follows [36]:

$$
\begin{aligned}
& H=f(x)= \\
& \left\{\begin{array}{cl}
R_{0}(\varnothing) \times A_{\text {eff }}(\psi), & 0 \leq \psi<\psi_{c} \\
0, & \psi \geq \psi_{c}
\end{array}\right.
\end{aligned}
$$

Here, $\mathrm{R}_{0}(\varnothing)$ and $\mathrm{A}_{\mathrm{eff}}(\psi)$ represent the transmitter radiant intensity and the effective signal collection area, respectively, which are defined as:

$$
\begin{gathered}
R_{0}(\varnothing)=\frac{(v+1)}{2 \pi} \times \cos ^{v}(\varnothing) \\
A_{e f f}(\psi)= \\
A \times \cos (\psi) \times T_{S}(\psi) \times g(\psi)
\end{gathered}
$$

Where $\varnothing$ the radiation angle for the transmitter vertical axis is, $\psi$ is the incidence angle for the receiver. Given in Eq. $(10), \mathrm{T}_{\mathrm{S}}(\psi)$ denotes the optical filter gain and $\mathrm{g}(\psi)$ denotes the concentrator gain which is expressed as:

$$
g(\psi)=\left(\frac{\eta c}{\sin (\psi)}\right)^{2}
$$

In Eq. (11), $\eta c$ is the internal refractive index and $\psi_{\mathrm{c}}$ is the concentrator FOV (Field Of View). The coverage area of an optical receiver is limited by its FoV, which affects the range of localizations. The Lambertian order $\mathrm{v}$ is calculated in Eq. (12) as:

$$
v=\frac{-\ln (2)}{\ln \left(\cos \left(\emptyset_{\frac{1}{2}}\right)\right)}
$$

Where $\emptyset_{\frac{1}{2}}$ is the transmitters' semi-angle at half power. The received optical power for the VLC (Visible Light Communication) network, also known as RSS, from the LED in a line-of-sight environment 
can be written as based on the channel model show the RSS in Eq. (13):

$$
P R_{i}=\frac{H_{i} \times P_{T}}{d_{x y_{i}^{2}}}
$$

The only measurements of received optical power that can be seen are the noisy ones. As a result, the above identity can be modeled as follows in Eq. (14), taking into account the noise term, symbolized $\partial_{\mathrm{i}}^{2}$.

$$
P R_{i}=\frac{H_{i} \times P_{T}}{d_{x y_{i}^{2}}}+\partial_{i}^{2}
$$

Where $\partial_{\mathrm{i}}^{2} \mathrm{I} \sim \mathrm{N}(0, \partial 2 \mathrm{i})$ represents zero-additive Gaussian noise with two constants. The probability function of the RSS notes is expressed in favor of an unknown received site as it is for a VLC network, using an added Gaussian noise distribution [29], and can be expressed in the Eq. (15):

$$
\partial_{i}^{2}=\partial_{\text {shot }}^{2}+\partial_{\text {thermal }}^{2}
$$

$\partial_{\text {shot }}^{2}$ and $\partial_{\text {thermal }}^{2}$ Are defined as in Eqs. (16) (17):

$$
\begin{gathered}
\begin{array}{r}
\partial_{\text {shot }}^{2}=2 \times q \times r \times p_{r}+2 \times \\
\times I_{2} \times B \times I_{b g}
\end{array} \\
\partial_{\text {thermal }}^{2}=\frac{8 \pi \times k \times T_{K}}{G_{0}} \times \eta \times A \times I_{2} \times B^{2}+ \\
\frac{16 \pi^{2} \times k \times T_{K} \times L}{g_{m}} \times \eta \times A \times I_{3} \times B^{3}
\end{gathered}
$$

where $r, q, B, k, I_{b g}, T_{K}, G_{0}, L, \eta$ and $g_{m}$ is the responsivity of the photodiode, elementary charge, equivalent noise bandwidth, Boltzmann's constant, background current, absolute temperature, the openloop voltage gain, the channel noise factor, the fixed capacitance of photodetector and trans-conductance, respectively; $\mathrm{I}_{2}$ and $\mathrm{I}_{3}$ are the noise bandwidth factors.

\section{Three-dimensional positioning algorithm based on DNN}

This section used a deep learning algorithm to implement the location accuracy based on the indoor Li-Fi network, depending on the simulated data using the RSS-triangulation method. A deep neural network (DNN) consists of artificial neural network (ANN) nodes in different hierarchical layers. These layers consist of the input layer, hidden layers, and the output layer.

The input layer as its name would suggest, represents network input, the network stimulus is described as follows in Eq. (18):

$$
h^{0}=x
$$

The distance between the LED and user locations extracted from the RSS-triangulation method is an input for the DNN. While hidden layers perform a non-linear operation using the output of the previous layer. It is described as follows in Eq. (19):

$$
h^{k}=f\left(W^{k} h^{k-1} b^{k}\right)
$$

Where $\mathrm{W}^{\mathrm{k}}$ is the matrix of weights that represents all the synaptic connections between each neuron from layer $\mathrm{k}-1$ and each neuron from the layer. $b^{k}$ is the bias vector of layer $\mathrm{k} . \mathrm{h}^{\mathrm{k}-1}$ represents the output from the previous layer and $\mathrm{f}$ (net) is the activation function that represents the non-linear relationship within the layer [37].

The output of the DNN represents the user locations (X, Y, and Z), and bipolar- sigmoid Activation Function were used within our work. In the following sub-sections were explained, the bipolar-sigmoid activation and ADAM optimizer function.

\subsection{Bipolar-sigmoid activation function}

The activation function has two types, namely linear activation function, and non-linear activation function. In general, neural networks use nonlinear activation functions, which can help the network, learn complex data, calculate and learn almost any function that represents a question, and make accurate predictions. It allows inverse propagation because it has a derivative function associated with the input.

Our work used a bipolar-sigmoidal activation function that takes a real value as input and gives the probability that it is always between 0 and 1 . It looks like an "S" shape [38]. Where Fig. 4 below represents the function of the bipolar-sigmoid function and shows its function Eq. (20) and derivation Eq. (21).

$$
\begin{aligned}
f(\text { net })= & \frac{1}{1+e^{-n e t}} \\
f^{\prime}(\text { net }) & =\frac{1}{2} . \\
& \left(1-f(\text { net })^{2}\right.
\end{aligned}
$$




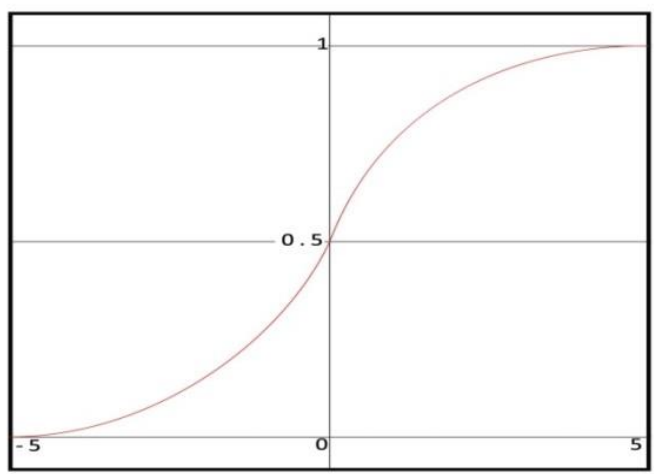

Figure. 4 Bipolar- sigmoid activation function

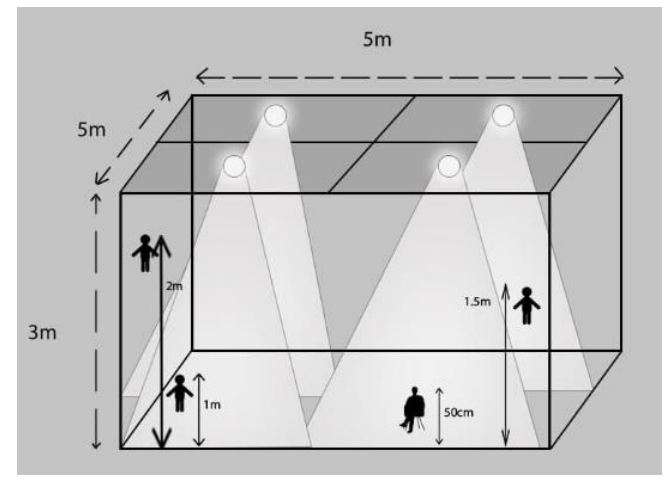

Figure. 5 Indoor Li-Fi simulation

The time of this function is non-linear, continuously differentiable, monotonous, and has a fixed output range. The main feature of this function is simple and good for the workbook [38].

\subsection{ADAM optimizer}

This research proposes Adam, a method for efficient stochastic optimization that only requires first-order gradients with little memory requirement. The method computes individual adaptive learning rates for different parameters from estimates of first and second moments of the gradients; the name Adam is derived from adaptive moment estimation. Adam optimizer is worked to combine the advantages of two recently popular methods: ADAGRAD [39], which works well with sparse gradients, and RMSProp [40], which works well in online and non-stationary settings. Some of Adam's advantages are that the magnitudes of parameter updates are invariant to rescaling of the gradient, its step sizes area approximately bounded by the step size hyperparameter, it does not require a stationary objective, it works with sparse gradients, and it naturally performs a form of step size annealing.

ADAM Optimizer can be implemented with several steps and equations, where shown in Eq. (22) how gradients are obtained concerning the random target at time step t.

$$
g t=\Delta_{\theta} f_{t}\left(\theta_{t}-1\right)
$$

Eq. (23) shows to calculate the biased data to estimate the first moment, first-moment vector, while Eq. (24) is to calculate the biased data to estimate the first moment, the second-moment vector.

$$
\begin{aligned}
& m t=\beta_{1} \cdot m t-1+\left(1-\beta_{1}\right) \cdot g t \\
& v t=\beta_{2} \cdot v t-1+\left(1-\beta_{2}\right) \cdot g t^{2}
\end{aligned}
$$

As for Eq. (25) calculating the first-moment vector corrected for bias and Eq. (26) calculating the second-moment vector corrected for bias.

$$
\begin{gathered}
\widehat{m t} \leftarrow m t /\left(1-\beta_{1}^{2}\right) \\
\widehat{v t} \leftarrow v t /\left(1-\beta_{2} t\right)
\end{gathered}
$$

Finally, the Up data parameter (the resulting parameters) can be calculated through Eq. (27):

$$
\theta_{t}=\theta_{t-1}-\alpha \cdot \widehat{m t} / \sqrt{\widehat{v t}}+\epsilon
$$

Good default settings for the tested DNN learning problems are $\alpha=0.001$ is represented step size, $\beta_{1}=$ $0.9, \beta_{2}=0.999$ and $\epsilon=10-8$. All operations on vectors are element-wise [41].

\section{The methodology of Li-Fi simulation model}

To implement the aim of indoor Li-Fi localization system using RSS-Triangulation with higher accuracy, a faster time, and lower cost in the indoor environment that consists of four LEDs ceilingmounted and the user's position $(\mathrm{x}, \mathrm{y}, \mathrm{z})$ is unknown in the room as shown in Fig. 5.

The 2019 version of MATLAB was used to implement the two-stage user location calculation methodology. Where the first stage is a presentation of the method used in our work without noise to simulate the data (simulation of the Li-Fi sensor) based on the triangulation method and calculating the error location for the user as shown in Fig. 6.

As for the second stage, it was under the influence of noise, which is to perform a simulation of the data based on the strength of the received signal - triangulation to determine: the user's location, distance error, received power, and the angle of incidence as shown in Fig. 7. While Table 2 shows the parameters for the 3D indoor $\mathrm{Li}-\mathrm{Fi}$ system utilizing the RSS - Triangulation mode. 


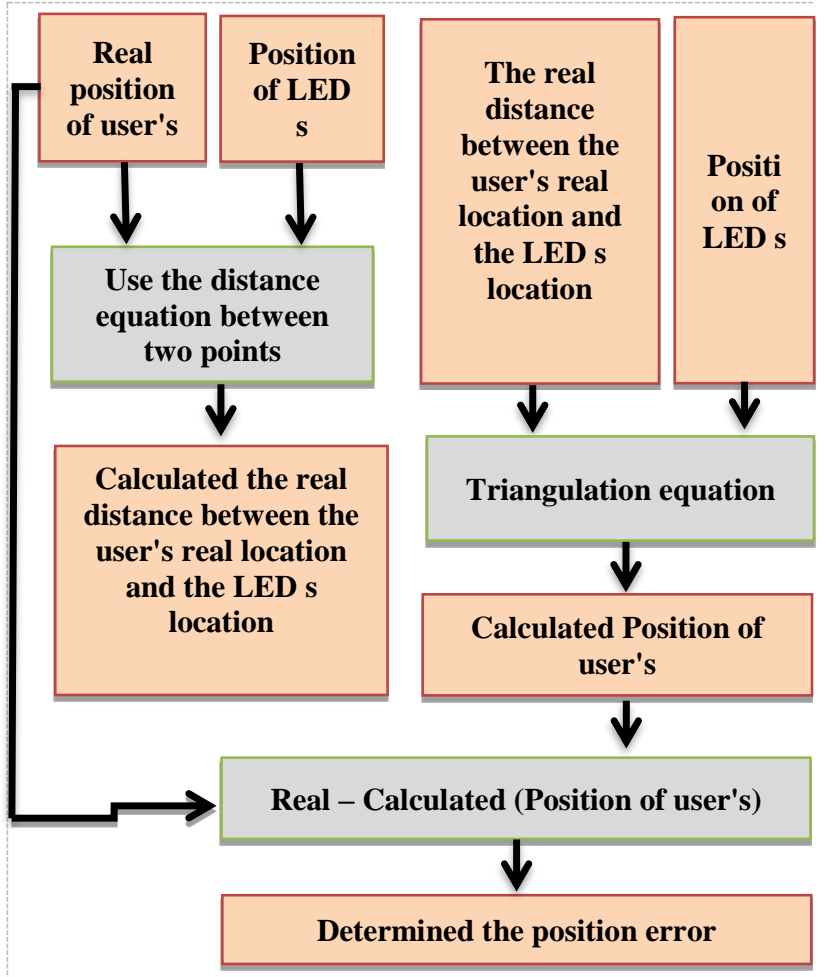

Figure. 6 Flowchart for the sequence of our work in the triangulation method

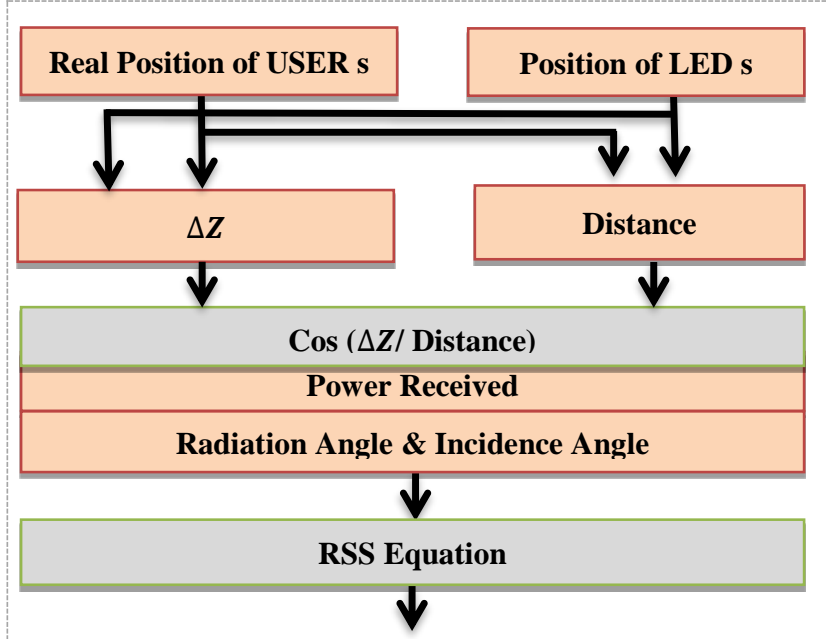

Figure. 7 Flowchart for the sequence of our work in the RSS- triangulation method

After simulating the data based on the RSS method, the data (distance) was implemented as input to the deep learning algorithm to determine the accuracy of the user's location as shown in the flowchart in Fig 8. Where Table 3 shows the specifications of the DNN based on RSS- triangulation.
Table 2. Parameters of Li-Fi simulation

\begin{tabular}{|c|c|c|}
\hline Parameters & Symbol & Value \\
\hline $\begin{array}{l}\text { Room } \\
\text { dimensions }\end{array}$ & $(\mathrm{L}, \mathrm{W}, \mathrm{H})$ & $5 \mathrm{~m} \times 5 \mathrm{~m} \times 3 \mathrm{~m}$ \\
\hline $\begin{array}{l}\text { Power of } \\
\text { each LED }\end{array}$ & $P_{T}$ & 2 Watt \\
\hline $\begin{array}{l}\text { Position of } \\
\text { each LED }\end{array}$ & $(x-y-z)$ & $\begin{array}{l}\text { LED1 }(1.25 \mathrm{~m}, 1.25 \mathrm{~m}, \\
3 \mathrm{~m}) \\
\text { LED2 } \\
\text { 3m) } \\
\text { LED3 }(1.25 \mathrm{~m}, 3.75 \mathrm{~m} \text {, } \\
\text { 3m) } \\
\text { LED4 }(3.75 \mathrm{~m}, 3.75 \mathrm{~m}, \\
\text { 3m) }\end{array}$ \\
\hline $\begin{array}{l}\text { Rang upper } \\
\text { and lower of } \\
\text { user location }\end{array}$ & $(x-y-z)$ & $\begin{array}{l}\text { upper }=(5 \mathrm{~m}, 5 \mathrm{~m}, 2.8 \mathrm{~m}) \\
\text { lower }=(0 \mathrm{~m}, 0 \mathrm{~m}, 0 \mathrm{~m})\end{array}$ \\
\hline $\begin{array}{l}\text { Field of } \\
\text { View to } \\
\text { Receiver }\end{array}$ & FOV & 70 degree \\
\hline $\begin{array}{l}\text { Lambertian } \\
\text { order }\end{array}$ & $v$ & 1 \\
\hline $\begin{array}{l}\text { Photodetect } \\
\text { or area }\end{array}$ & $A$ & $1 \mathrm{~cm} 2$ \\
\hline $\begin{array}{l}\text { The optical } \\
\text { filter gain }\end{array}$ & $T_{S}$ & 1 \\
\hline $\begin{array}{l}\text { the internal } \\
\text { refractive } \\
\text { index }\end{array}$ & $\eta c$ & 1.7 \\
\hline $\begin{array}{l}\text { Boltzmann's } \\
\text { constant }\end{array}$ & $K$ & $1.3806505 \times 10^{-23}$ \\
\hline $\begin{array}{l}\text { Equivalent } \\
\text { noise } \\
\text { bandwidth }\end{array}$ & $B$ & $7 \times 10^{6} \mathrm{HZ}$ \\
\hline $\begin{array}{l}\text { Absolute } \\
\text { temperature }\end{array}$ & $T_{k}$ & $295 \mathrm{~K}$ \\
\hline $\begin{array}{l}\text { Open-loop } \\
\text { voltage gain }\end{array}$ & $G_{0}$ & 10 \\
\hline $\begin{array}{l}\text { the field- } \\
\text { effect } \\
\text { transistor of } \\
\text { trans- } \\
\text { conductance }\end{array}$ & $g_{m}$ & $30 \mathrm{mS}$ \\
\hline $\begin{array}{l}\text { the field- } \\
\text { effect } \\
\text { transistor of } \\
\text { channel } \\
\text { noise Factor }\end{array}$ & $L$ & 1.5 \\
\hline $\begin{array}{l}\text { Noise } \\
\text { bandwidth } \\
\text { factor }\end{array}$ & $I_{2}$ & 0.562 \\
\hline $\begin{array}{l}\text { Noise } \\
\text { bandwidth } \\
\text { factor }\end{array}$ & $I_{3}$ & 0.0868 \\
\hline $\begin{array}{l}\text { Fixed } \\
\text { capacitance }\end{array}$ & 0 & $112 \mathrm{pF} \mathrm{cm}^{-2}$ \\
\hline $\begin{array}{l}\text { Background } \\
\text { current }\end{array}$ & $I_{b g}$ & 20 \\
\hline
\end{tabular}


Table 3. Deep neural network specification based on RSS- triangulation

\begin{tabular}{|c|c|}
\hline Deep Neural Network & specification \\
\hline Number of input layers & 4 \\
\hline Number of hidden layers & 9 \\
\hline Hidden layers size & $\begin{array}{c}(84,84,84,84,84,84,84,84, \\
84)\end{array}$ \\
\hline Total number of neurons & 756 \\
\hline $\begin{array}{c}\text { Number of output } \\
\text { layers }\end{array}$ & 3 \\
\hline $\begin{array}{c}\text { The percentage of data } \\
\text { used in our work }\end{array}$ & 90000 \\
\hline $\begin{array}{c}\text { Percentage of samples } \\
\text { for training }\end{array}$ & $70 \%$ \\
\hline $\begin{array}{c}\text { Percentage of samples } \\
\text { for testing }\end{array}$ & $30 \%$ \\
\hline Activation function & Bipolar- Sigmoid \\
\hline Optimizer & ADAM \\
\hline Training algorithm & Backpropagation \\
\hline Alpha parameter & 0.1 \\
\hline Learning rate & 0.01 \\
\hline Epoch rate & 300,000 \\
\hline
\end{tabular}

\section{Simulation results and analysis}

In this section, we present a performance analysis of our proposed methodology introduced in section 4, where two approaches used for internal LiFi localization are adopted.

In the first approach, the simulation results were discussed, the method used in our work, which is triangulation and without the influence of noise, as there is no place free from noise, but in this approach a presentation of the method used and proof of its validity to be adopted in the second approach.

In the second approach, the simulation results discussed the data based on the RSS-Triangulation method and in the presence of noise where this distance data was studied and tested using a deep learning algorithm to calculate the accuracy of the user's location. The results of the methodology are explained in the following sections:

\subsection{Simulation result of triangulation method}

This section presents the results of simulated the triangulation method in user locating within our workroom, by applying the equations explained in section 3 without the influence of noise. Were used 90,000 user sites, and we displayed (1-200) of these sites within the view results.

Fig. 9 shows the results of applying this method, where the blue color represents the LEDs location and the red color represents the real user location,

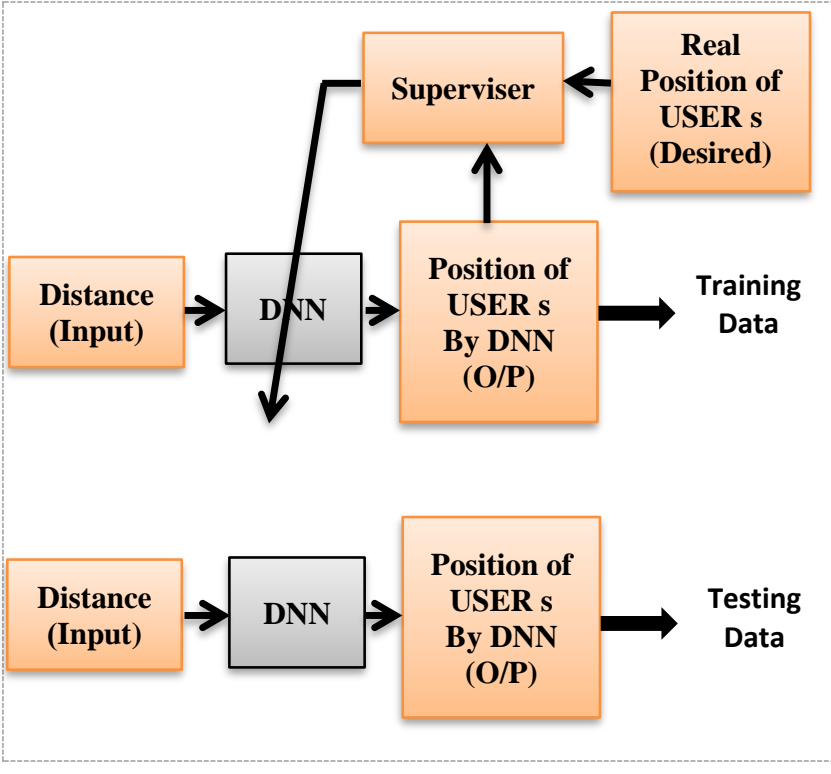

Figure. 8 Flowchart for the proposed DNN sequence based on RSS- triangulation method

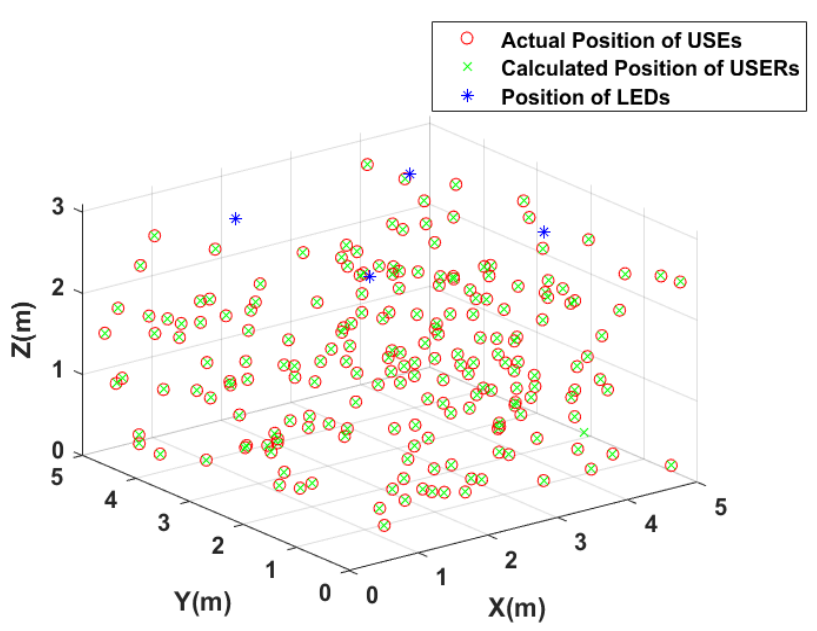

Figure. 9 The real user location and the calculated user location by triangulation

while the green color indicates the calculated user location by using triangulation. wherein Fig. 10 show the location error rate in all axes (x,y, and $\mathrm{z})$, while Table 4 shows the average site error, maximum and minimum at the error location these results are the optimal results obtained and the reason is due to the absence of the presence of noise and the correctness of our implementation of the triangulation method.

\subsection{Simulation result of RSS-triangulation method}

After showing and testing our method based on triangulation without the influence of noise, we studied in this section our method under the influence of noise using RSS -Triangulation, as the details of 

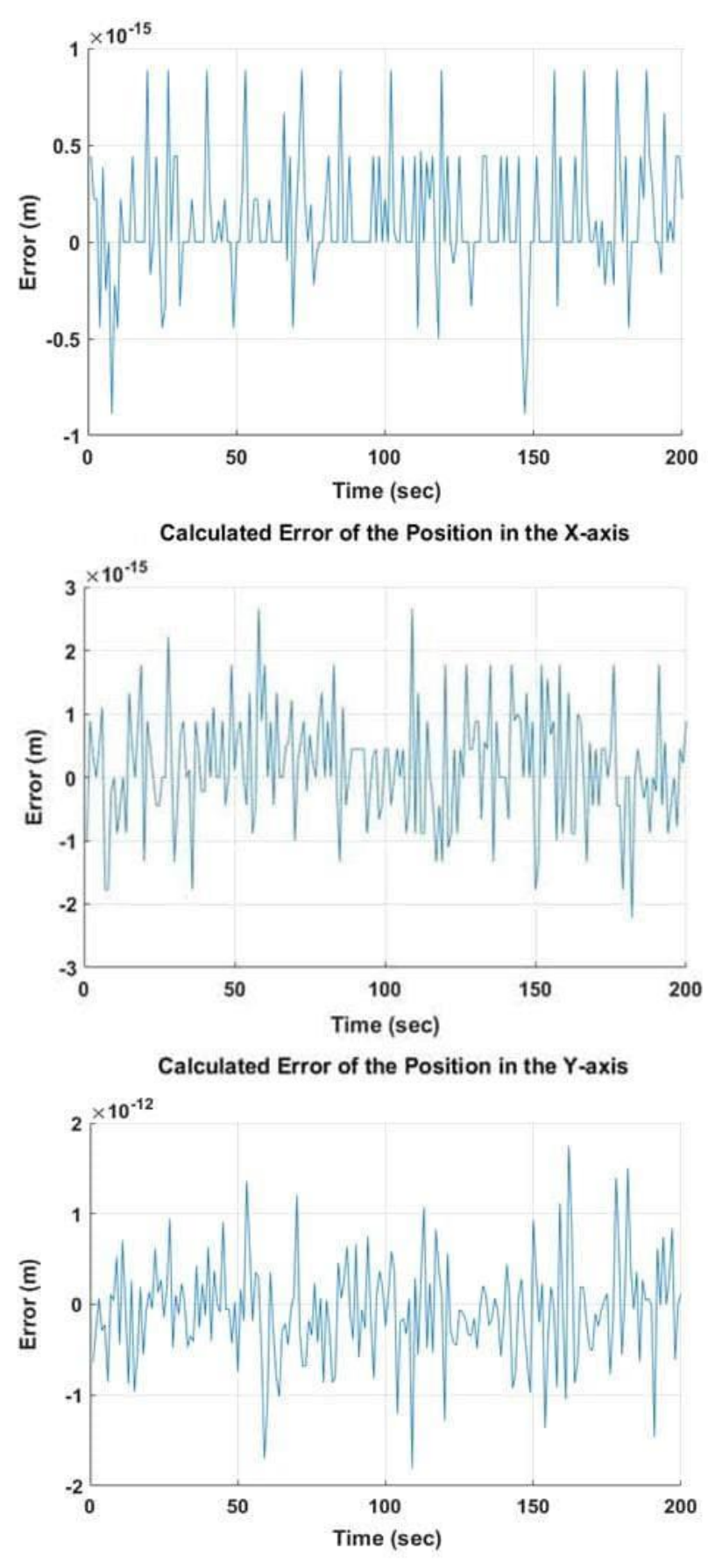

Calculated Error of the Position in the Z-axis

Figure. 10 Position error ratio in The $\mathrm{X}, \mathrm{Y}$ and $\mathrm{Z}$ axis using the triangulation method

the method with its equations were explained in section 2.2.3.

Fig. 11 below shows the results of our use of the RSS -Triangulation method, were used 90,000 user sites, and we displayed (1-200) of these sites within the view results. Where the blue color represents the LED location and the red color represents the user location that was calculated by RSS -Triangulation, while the green color shows the user location that was
Table 4. Error localization for triangulation method

\begin{tabular}{|c|c|c|c|}
\hline Axis & $\begin{array}{c}\text { Average } \\
\text { Error }\end{array}$ & $\begin{array}{c}\text { Maximum } \\
\text { Error }\end{array}$ & $\begin{array}{l}\text { Minimum } \\
\text { Error }\end{array}$ \\
\hline $\mathrm{X}$-axis & $\begin{array}{c}2.17344 \\
\times 10^{-14} \\
\mathrm{~cm}\end{array}$ & $\begin{array}{l}1.77636 \times \\
10^{-13} \mathrm{~cm}\end{array}$ & $\begin{array}{c}-1.33227 \times \\
10^{-13} \mathrm{~cm}\end{array}$ \\
\hline$Y$-axis & $\begin{array}{c}6.44762 \\
\times 10^{-14} \\
\mathrm{~cm}\end{array}$ & $\begin{array}{c}4.44089 \times \\
10^{-13} \mathrm{~cm}\end{array}$ & $\begin{array}{c}-3.66374 \times \\
10^{-13} \mathrm{~cm}\end{array}$ \\
\hline Z-axis & $\begin{array}{c}4.65690 \\
\times 10^{-11} \\
\mathrm{~cm}\end{array}$ & $\begin{array}{c}3.45302 \times \\
10^{-10} \mathrm{~cm}\end{array}$ & $\begin{array}{l}-3.25429 \\
\times 10^{-10} \mathrm{~cm}\end{array}$ \\
\hline
\end{tabular}

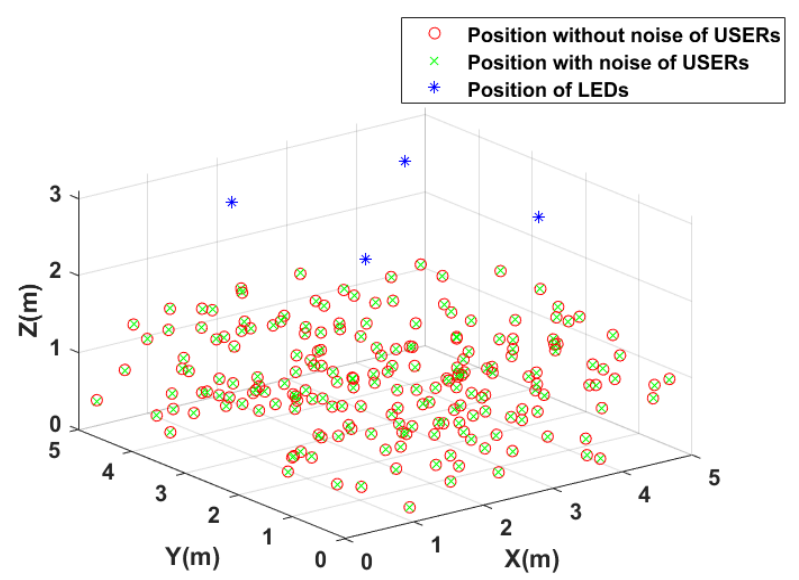

Figure. 11 The user's location based on the RSS method without the effect of noise and under the influence of noise

as the noise equations were explained in section 2.4, Eqs. (15), (16) and (17).

Fig. 12 shows the effect of noise in the X-Y-Z axes of the user's location by adopting the RSStriangulation method, while Table 5 shows the average location error, the maximum and minimum of error in $\mathrm{X}-\mathrm{Y}-\mathrm{Z}$ axes for the user, and we note the effect of noise also on the distance between the LEDs locations and the user locations in Fig. 13 where it displays Table 6 the average distance error between all LEDs location and all user locations, as well as the maximum and minimum distance error.

In Fig. 14 we showed the optical power received from the LEDs for each user inside the workroom where Table 7 shows the average power received as well as the maximum and minimum power received from all LEDs.

The incidence angle for light power must be taken into computation, so we presented in Fig. 15 the angle of incidence of the LEDs at each user location as we mentioned previously, the results were shown for data only from 1 to 200 locations out of 90,000 locations for the user, and we explained in Table 8 

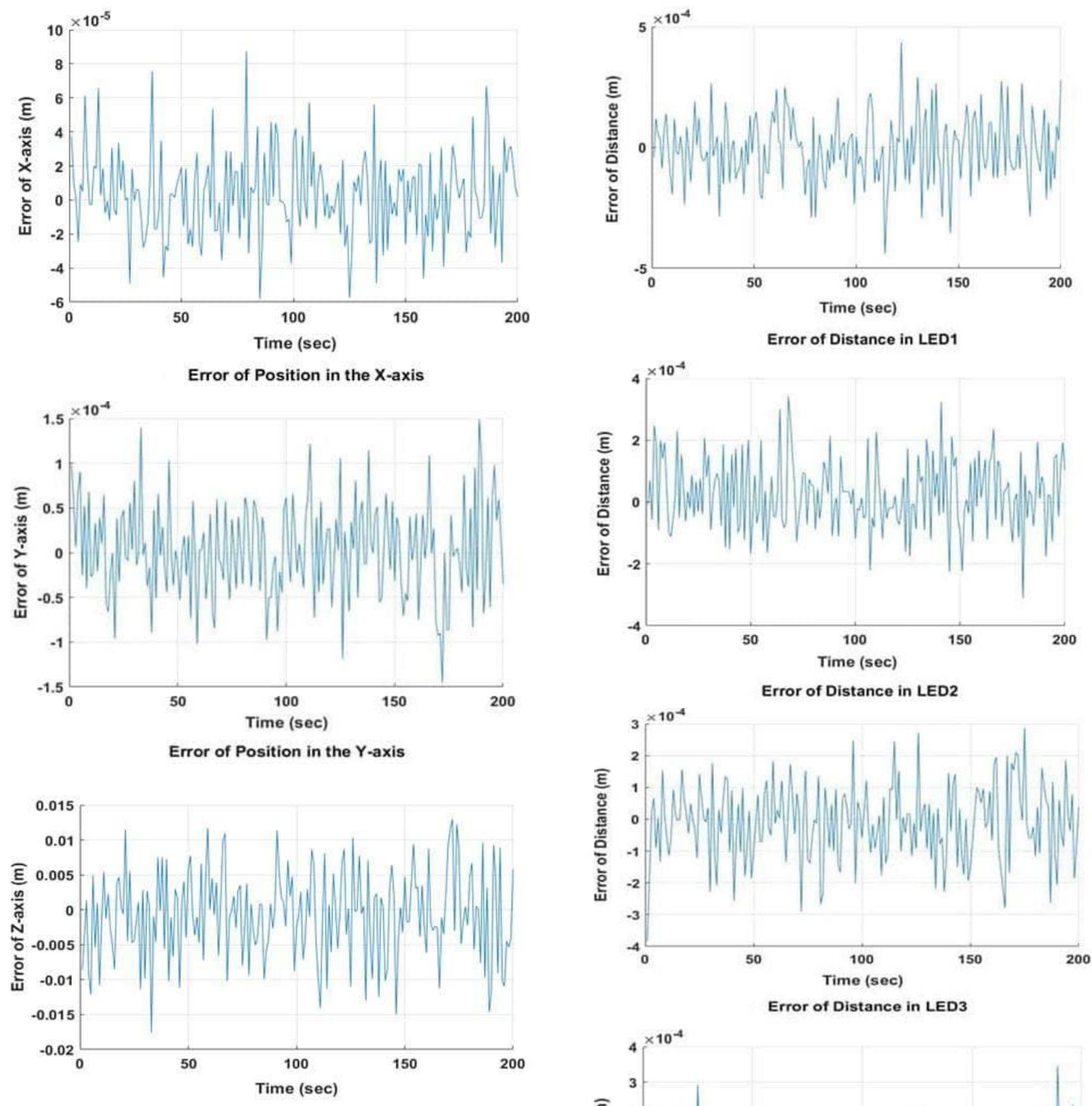

Error of Position in the Z-axis

Figure. 12 The effect of noise on the $\mathrm{X}, \mathrm{Y}$ and $\mathrm{Z}$ axes of the user's location based on the RSS -triangulation method

Table 5. Error localization for RSS -triangulation method

\begin{tabular}{|c|c|c|c|}
\hline Axis & $\begin{array}{c}\text { Average } \\
\text { Error }\end{array}$ & $\begin{array}{c}\text { Maximu } \\
\text { m Error }\end{array}$ & $\begin{array}{c}\text { Minimum } \\
\text { Error }\end{array}$ \\
\hline X-axis & $\begin{array}{c}2.05612 \\
\times 10^{-3} \mathrm{~cm}\end{array}$ & $\begin{array}{c}1.11197 \\
\times 10^{-2} \mathrm{~cm}\end{array}$ & $\begin{array}{c}-1.14502 \\
\times 10^{-2} \mathrm{~cm}\end{array}$ \\
\hline \multirow{2}{*}{ Y-axis } & $\begin{array}{c}4.56249 \\
\times 10^{-3} \mathrm{~cm}\end{array}$ & $\begin{array}{c}2.30044 \\
\times 10^{-2} \mathrm{~cm}\end{array}$ & $\begin{array}{c}-2.35818 \\
\times 10^{-2} \mathrm{~cm}\end{array}$ \\
\hline \multirow{2}{*}{ Z-axis } & $\begin{array}{c}5.10474 \\
\times 10^{-1} \mathrm{~cm}\end{array}$ & $\begin{array}{c}2.57736 \\
\mathrm{~cm}\end{array}$ & $\begin{array}{c}-2.64951 \\
\mathrm{~cm}\end{array}$ \\
\hline
\end{tabular}

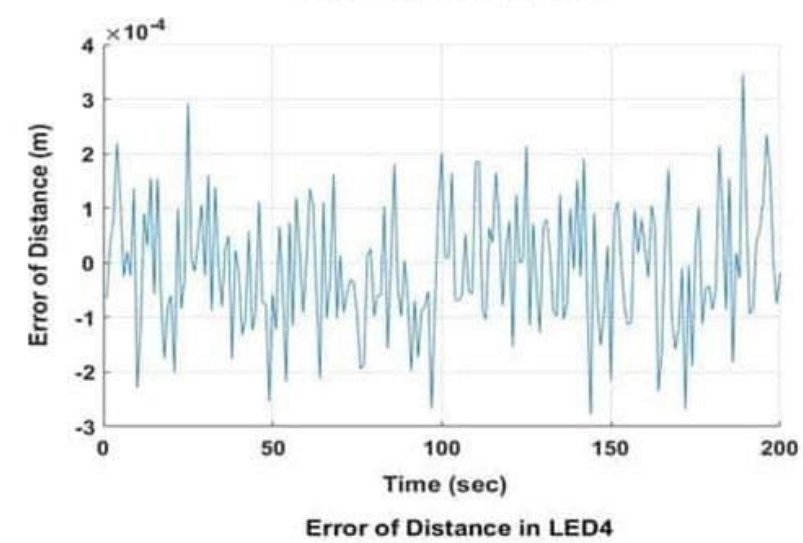

Figure. 13 Effect of noise on the distance between LEDs and user's location based on the RSS-triangulation method

the average incidence angle and the maximum and minimum of these angles. 

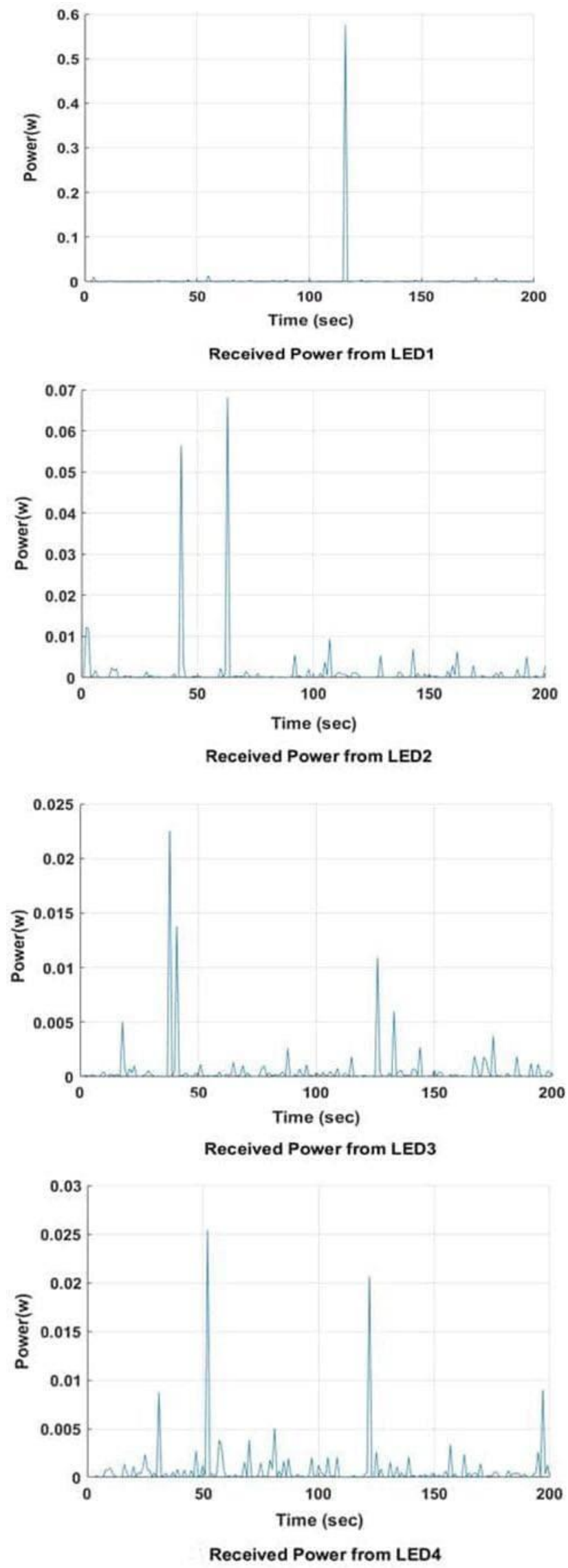

Figure. 14 The optical received power from LEDs for each user's
Table 6. Distance error between LEDs location and user's locations based on the RSS -triangulation method

\begin{tabular}{|c|c|c|}
\hline \multicolumn{3}{|c|}{$\begin{array}{c}\text { Distance Error } \\
\text { User's Locations }\end{array}$} \\
\hline Average & Maximum & Minimum \\
Distance & $\begin{array}{c}\text { Distance } \\
\text { Distance } \\
\text { Error }\end{array}$ & $\begin{array}{c}\text { Error } \\
\text { Error }\end{array}$ \\
\hline $1.02489 \times$ & $5.25929 \times$ & $-4.97112 \times$ \\
$\mathbf{1 0}^{-2} \mathrm{~cm}$ & $10^{-2} \mathrm{~cm}$ & $10^{-2} \mathrm{~cm}$ \\
\hline
\end{tabular}

\begin{tabular}{|c|c|c|}
\hline \multicolumn{3}{|c|}{$\begin{array}{c}\text { Distance Error between LED } 3 \text { Location and } \\
\text { User's Locations }\end{array}$} \\
\hline $\begin{array}{c}\text { Average } \\
\text { Distance } \\
\text { Error }\end{array}$ & $\begin{array}{c}\text { Maximum } \\
\text { Distance } \\
\text { Error }\end{array}$ & $\begin{array}{c}\text { Minimum } \\
\text { Distance } \\
\text { Error }\end{array}$ \\
\hline $\begin{array}{l}1.02125 \times \\
\mathbf{1 0}^{-2} \mathrm{~cm}\end{array}$ & $\begin{array}{c}5.68236 \times \\
10^{-2} \mathrm{~cm}\end{array}$ & $\begin{array}{l}-5.28430 \times \\
10^{-2} \mathrm{~cm}\end{array}$ \\
\hline
\end{tabular}

\begin{tabular}{|c|c|c|}
\hline \multicolumn{3}{|c|}{$\begin{array}{c}\text { Distance Error between LED } 2 \text { Location and } \\
\text { User's Locations }\end{array}$} \\
\hline $\begin{array}{c}\text { Average } \\
\text { Distance } \\
\text { Error }\end{array}$ & $\begin{array}{c}\text { Maximum } \\
\text { Distance } \\
\text { Error }\end{array}$ & $\begin{array}{c}\text { Minimum } \\
\text { Distance } \\
\text { Error }\end{array}$ \\
\hline $\begin{array}{c}1.02003 \times \\
\mathbf{1 0}^{-2} \mathrm{~cm}\end{array}$ & $\begin{array}{c}5.68109 \times \\
10^{-2} \mathrm{~cm}\end{array}$ & $\begin{array}{c}-6.47339 \times \\
10^{-2} \mathrm{~cm}\end{array}$ \\
\hline
\end{tabular}

\begin{tabular}{|c|c|c|}
\hline \multicolumn{3}{|c|}{$\begin{array}{c}\text { Distance Error between LED } 4 \text { Location and } \\
\text { User's Locations }\end{array}$} \\
\hline $\begin{array}{c}\text { Average } \\
\text { Distance } \\
\text { Error } \\
\end{array}$ & $\begin{array}{c}\text { Maximum } \\
\text { Distance } \\
\text { Error } \\
\end{array}$ & $\begin{array}{c}\text { Minimum } \\
\text { Distance } \\
\text { Error }\end{array}$ \\
\hline $\begin{array}{c}1.02408 \times \\
\mathbf{1 0}^{-2} \mathrm{~cm}\end{array}$ & $\begin{array}{c}5.40086 \times \\
10^{-2} \mathrm{~cm}\end{array}$ & $\begin{aligned}- & 5.66784 \times \\
& 10^{-2} \mathrm{~cm}\end{aligned}$ \\
\hline
\end{tabular}

\subsection{DNN simulation results for RSS-triangulation distance data}

After simulating the data in section 4.2 in locating the user in an indoor environment depending on the RSS-triangulation method and under the influence of noise, the distance data was studied and tested on a deep learning algorithm.

Fig. 16 shows the performance implementation of the deep learning algorithm in the distance data with noise that results from the RSS- triangulation simulation under certain characteristics as in Table 3, where these characteristics were adopted by several experiments and tests to obtain the best results.

Table 9 presents the results of training the distance data with noise in our working room more precisely on the (X-Y and Z) axes between the actual location and the estimated location from the deep learning algorithm. where showed the amount of the mean of the error, the standard deviation of the error, the minimum and maximum error in each axis, It was 
Table 7. The average received power from the LEDs, the maximum and minimum received power for photo detector

\begin{tabular}{|c|c|c|}
\hline \multicolumn{2}{|c|}{ Received Power from LED 1 for Photodetector } \\
\hline $\begin{array}{c}\text { Average } \\
\text { Received } \\
\text { Power }\end{array}$ & $\begin{array}{c}\text { Maximum } \\
\text { Received } \\
\text { Power }\end{array}$ & $\begin{array}{c}\text { Minimum } \\
\text { Received } \\
\text { Power }\end{array}$ \\
\hline $1.47607 \times$ & 1.83483 & $6.19386 \times$ \\
$\mathbf{1 0}^{-3}$ Watt & Watt & $10^{-6}$ Watt \\
\hline
\end{tabular}

\begin{tabular}{|c|c|c|}
\hline \multicolumn{2}{|c|}{ Received Power from LED 2 for Photodetector } \\
\hline $\begin{array}{c}\text { Average } \\
\text { Received } \\
\text { Power }\end{array}$ & $\begin{array}{c}\text { Maximum } \\
\text { Received } \\
\text { Power }\end{array}$ & $\begin{array}{c}\text { Minimum } \\
\text { Received } \\
\text { Power }\end{array}$ \\
\hline $1.53278 \times$ & 1.95597 & $6.00296 \times$ \\
$\mathbf{1 0}^{-3}$ Watt & Watt & $10^{-6}$ Watt \\
\hline
\end{tabular}

\begin{tabular}{|c|c|c|}
\hline \multicolumn{2}{|c|}{ Received Power from LED 3 for Photodetector } \\
\hline $\begin{array}{c}\text { Average } \\
\text { Received } \\
\text { Power }\end{array}$ & $\begin{array}{c}\text { Maximum } \\
\text { Received } \\
\text { Power }\end{array}$ & $\begin{array}{c}\text { Minimum } \\
\text { Received } \\
\text { Power }\end{array}$ \\
\hline $1.38966 \times$ & 1.69117 & $6.30993 \times$ \\
$\mathbf{1 0}^{-\mathbf{3}}$ Watt & Watt & $10^{-6}$ Watt \\
\hline
\end{tabular}

\begin{tabular}{|c|c|c|}
\hline \multicolumn{2}{|c|}{ Received Power from LED 4 for Photodetector } \\
\hline $\begin{array}{c}\text { Average } \\
\text { Received } \\
\text { Power }\end{array}$ & $\begin{array}{c}\text { Maximum } \\
\text { Received } \\
\text { Power }\end{array}$ & $\begin{array}{c}\text { Minimum } \\
\text { Received } \\
\text { Power }\end{array}$ \\
\hline $1.41845 \times$ & 1.85245 & $6.09794 \times$ \\
$\mathbf{1 0}^{-3}$ Watt & Watt & $10^{-6}$ Watt \\
\hline
\end{tabular}
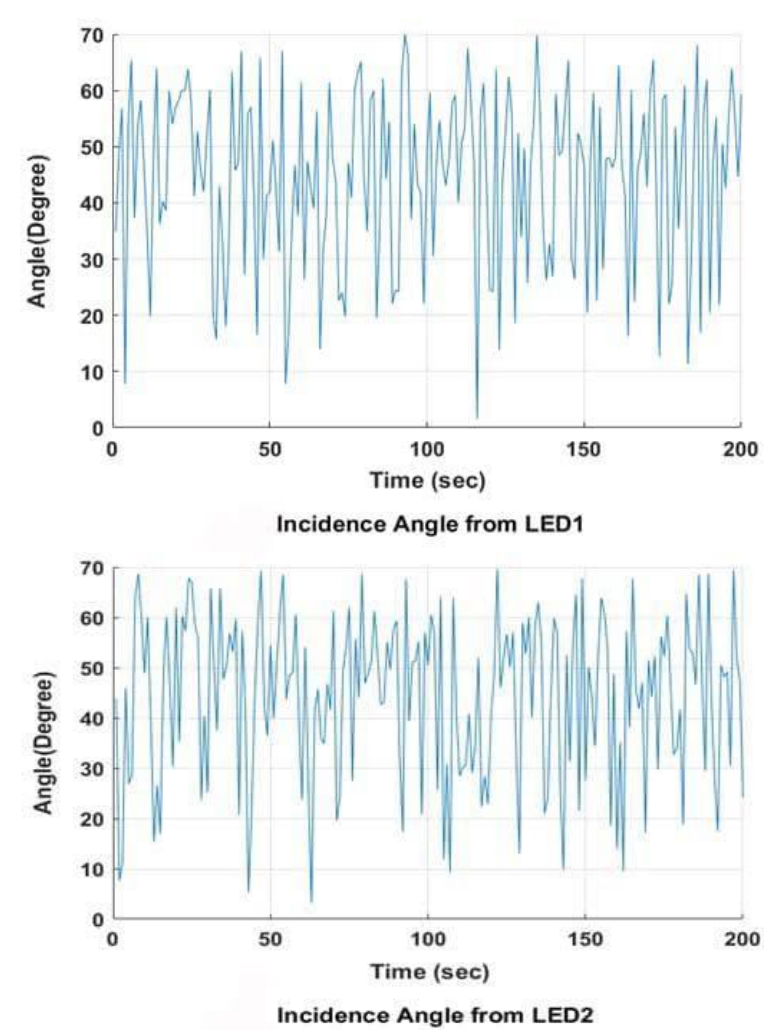

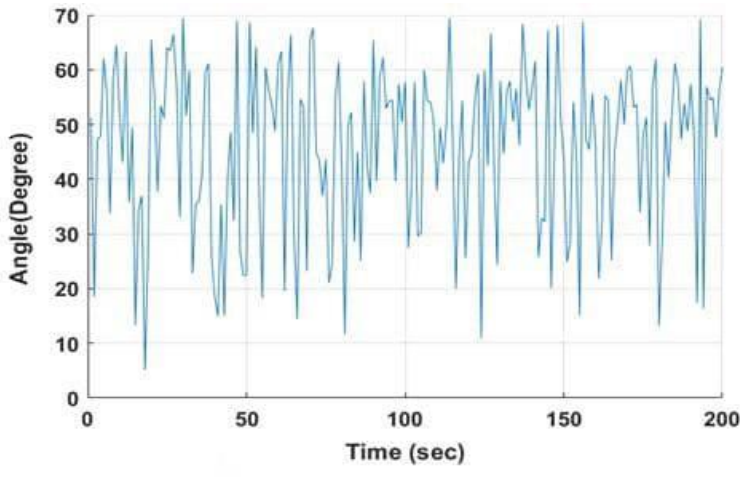

Incidence Angle from LED4

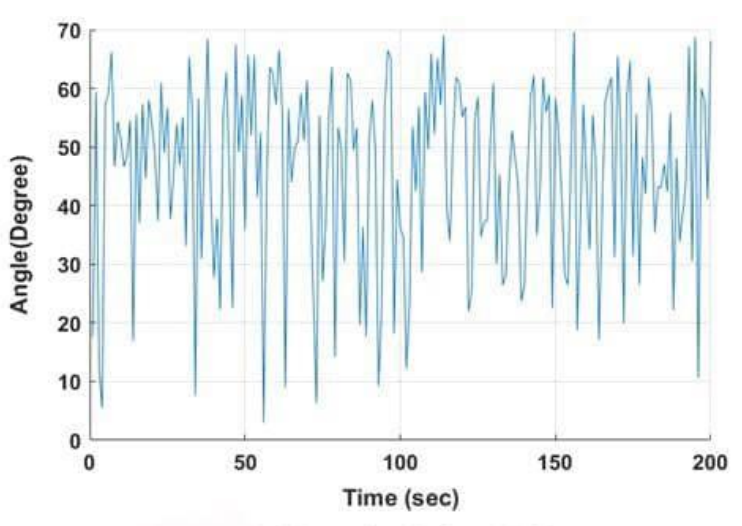

Incidence Angle from LED3

Figure. 15 The incidence angle from LEDs for each user's location

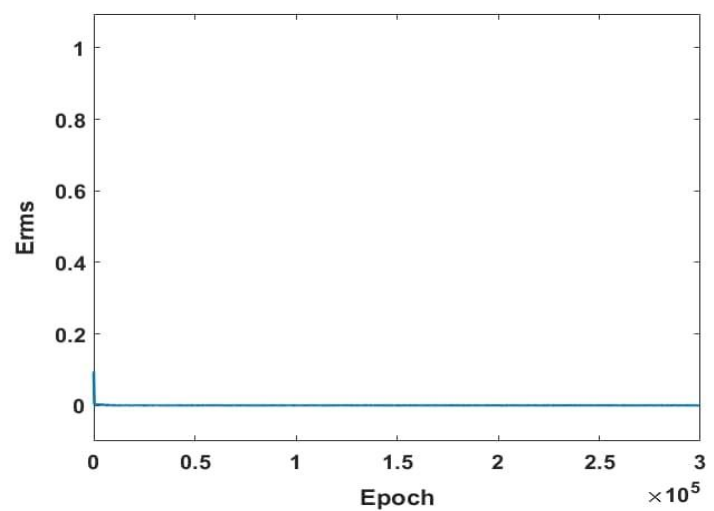

Figure. 16 The DNN performance to distance data

obtained this result after several attempts of training and organization of the characteristics of the DNN in 0.6 seconds.

Presented in Fig. 17 the results of testing the distance data and show Fig. 18 show us these results more precisely on the (X-Y and Z) axes between the actual location and the estimated location from the deep learning algorithm. While in Fig. 19 show the amount of error in each axis for the user sites, and Table 10 showed the amount of the mean of the error, the standard deviation of the error, the minimum and 
Table 8. The average incidence angle from the LEDs, the maximum and minimum incidence angle for user's location

\begin{tabular}{|c|c|c|}
\hline \multicolumn{3}{|c|}{ Average Incidence Angle from LED 1 for } \\
User's Location
\end{tabular}

\begin{tabular}{|c|c|c|}
\hline \multicolumn{3}{|c|}{$\begin{array}{c}\text { Average Incidence Angle from LED } 2 \text { for } \\
\text { User's Location }\end{array}$} \\
\hline $\begin{array}{c}\text { Average } \\
\text { Incidence } \\
\text { Angle }\end{array}$ & $\begin{array}{c}\text { Average } \\
\text { Incidence } \\
\text { Angle }\end{array}$ & $\begin{array}{c}\text { Average } \\
\text { Incidence } \\
\text { Angle }\end{array}$ \\
\hline $\begin{array}{c}4.53390 \times \\
\mathbf{1 0}^{+\mathbf{1}} \text { Degree }\end{array}$ & $\begin{array}{c}4.53390 \times \\
10^{+1} \text { Degree }\end{array}$ & $\begin{array}{c}4.53390 \times \\
10^{+1} \text { Degree }\end{array}$ \\
\hline
\end{tabular}

\begin{tabular}{|c|c|c|}
\hline \multicolumn{3}{|c|}{ Average Incidence Angle from LED 3 for } \\
User's Location
\end{tabular}

\begin{tabular}{|c|c|c|}
\hline \multicolumn{3}{|c|}{ Average Incidence Angle from LED 4 for } \\
User's Location \\
\hline $\begin{array}{c}\text { Average } \\
\text { Incidence }\end{array}$ & $\begin{array}{c}\text { Average } \\
\text { Incidence } \\
\text { Angle }\end{array}$ & $\begin{array}{c}\text { Average } \\
\text { Incidence } \\
\text { Angle }\end{array}$ \\
\hline Angle \\
\hline $4.54754 \times$ & 4.54754 & $4.54754 \times$ \\
$\mathbf{1 0}^{+1}$ Degree & $10^{+1}$ & $10^{+1}$ Degree \\
\hline
\end{tabular}

Table 9. Error ratios in the $x-y-z$ axis using DNN for

\begin{tabular}{|c|c|c|c|c|}
\hline Axis & $\begin{array}{l}\text { Mean } \\
\text { Error }\end{array}$ & $\begin{array}{c}\text { Standar } \\
\text { d } \\
\text { Deviatio } \\
\text { n Error }\end{array}$ & $\begin{array}{c}\text { Maximu } \\
\text { m } \\
\text { Error }\end{array}$ & $\begin{array}{c}\text { Minimum } \\
\text { Error }\end{array}$ \\
\hline $\begin{array}{l}\text { X- } \\
\text { axi } \\
\text { S }\end{array}$ & $\begin{array}{c}1.6750 \\
6 \times \\
10^{-3}\end{array}$ & $\begin{array}{c}2.1986 \\
8 \times \\
10^{-3}\end{array}$ & $\begin{array}{c}3.10615 \\
\mathrm{~cm}\end{array}$ & $\begin{array}{c}0.00000 \\
2 \mathrm{~cm}\end{array}$ \\
\hline $\begin{array}{l}\text { Y- } \\
\text { axi } \\
\text { S }\end{array}$ & $\begin{array}{c}1.4608 \\
6 \times \\
10^{-3}\end{array}$ & $\begin{array}{c}1.9544 \\
8 \times \\
10^{-3}\end{array}$ & $\begin{array}{c}2.84597 \\
\mathrm{~cm}\end{array}$ & $\begin{array}{c}0.00000 \\
1 \mathrm{~cm}\end{array}$ \\
\hline $\begin{array}{l}\text { Z- } \\
\text { axi } \\
\text { S }\end{array}$ & $\begin{array}{c}2.8686 \\
7 \times \\
10^{-3}\end{array}$ & $\begin{array}{c}4.0308 \\
8 \times \\
10^{-3}\end{array}$ & $\begin{array}{c}5.57300 \\
\mathrm{~cm}\end{array}$ & $\begin{array}{c}0.00000 \\
04 \mathrm{~cm}\end{array}$ \\
\hline
\end{tabular}

Table 10. Error ratios in the $x-y-z$ axis using DNN for

\begin{tabular}{|c|c|c|c|c|}
\hline \multicolumn{5}{|c|}{ Testing Destines Data } \\
\hline Axis & $\begin{array}{l}\text { Mean } \\
\text { Error }\end{array}$ & $\begin{array}{c}\text { Standar } \\
\text { d } \\
\text { Deviatio } \\
\text { n Error }\end{array}$ & $\begin{array}{l}\text { Maximu } \\
\text { m Error }\end{array}$ & $\begin{array}{c}\text { Minimum } \\
\text { Error }\end{array}$ \\
\hline $\begin{array}{c}X- \\
\text { axi } \\
\text { S }\end{array}$ & $\begin{array}{c}1.6864 \\
3 \times \\
10^{-3}\end{array}$ & $\begin{array}{c}2.2385 \\
5 \times \\
10^{-3}\end{array}$ & $\begin{array}{c}2.51535 \\
\mathrm{~cm}\end{array}$ & $\begin{array}{c}0.00000 \\
7 \mathrm{~cm}\end{array}$ \\
\hline $\begin{array}{c}Y- \\
\text { axi } \\
\text { S }\end{array}$ & $\begin{array}{c}1.4587 \\
6 \times \\
10^{-3}\end{array}$ & $\begin{array}{c}1.9481 \\
5 \times \\
10^{-3}\end{array}$ & $\begin{array}{c}2.25903 \\
\mathrm{~cm}\end{array}$ & $\begin{array}{c}0.00000 \\
06 \mathrm{~cm}\end{array}$ \\
\hline $\begin{array}{l}\text { Z- } \\
\text { axi } \\
\text { s }\end{array}$ & $\begin{array}{c}2.8554 \\
6 \times \\
10^{-3}\end{array}$ & $\begin{array}{c}3.9942 \\
9 \times \\
10^{-3}\end{array}$ & $\begin{array}{c}4.22898 \\
\mathrm{~cm}\end{array}$ & $\begin{array}{c}0.00000 \\
7 \mathrm{~cm}\end{array}$ \\
\hline
\end{tabular}

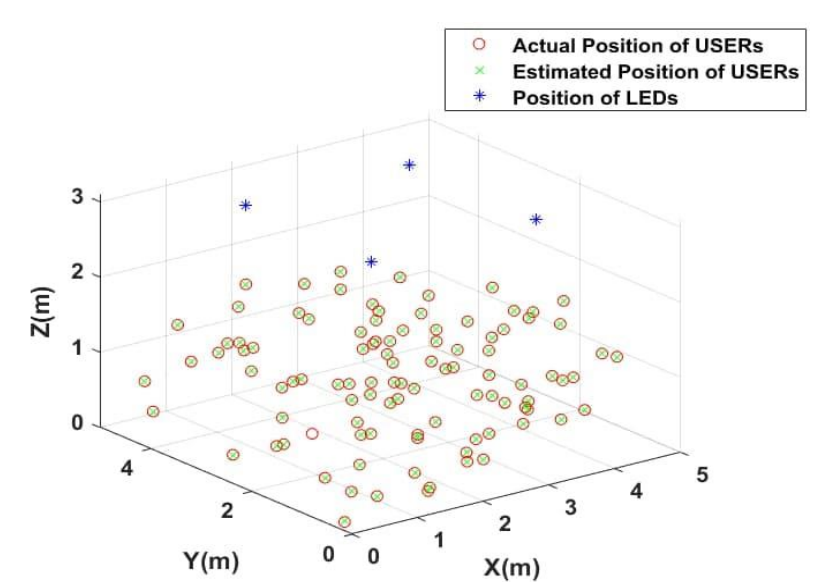

Figure. 17 The actual user location and the estimated user location using DNN for testing destines data

maximum error in each axis. Deep learning took 0.3 seconds to test the distance data with noise.

\section{Conclusion and future work}

This thesis presents the methodology of using the $\mathrm{Li}$-Fi wireless system based on the RSS-triangulation method in simulating the user's mobile location data and with the help of deep learning in determining the accuracy of the user's location in an indoor environment and based on matlab program, where the methodology was divided into two stages and each stage includes certain steps to simulate a user location where the feasibility of the proposed scheme has been sufficiently validated by tested and analysis of $3 \mathrm{D}$ user positioning performed in a $5 \times 5 \times 3$ space. Where the triangulation method was adopted without the effect of noise to prove the correctness of our work for the used method, where the error was calculated at the user's site (90,000 user sites) and the results of the method showed the amount of error in the $\mathrm{X}$-axis $2.17344 \times 10^{-14} \mathrm{~cm}, \mathrm{Y}$-axis $6.44762 \times$ $10^{-14} \mathrm{~cm}$ and Z-axis $4.656 \times 10^{-11} \mathrm{~cm}$. And the 


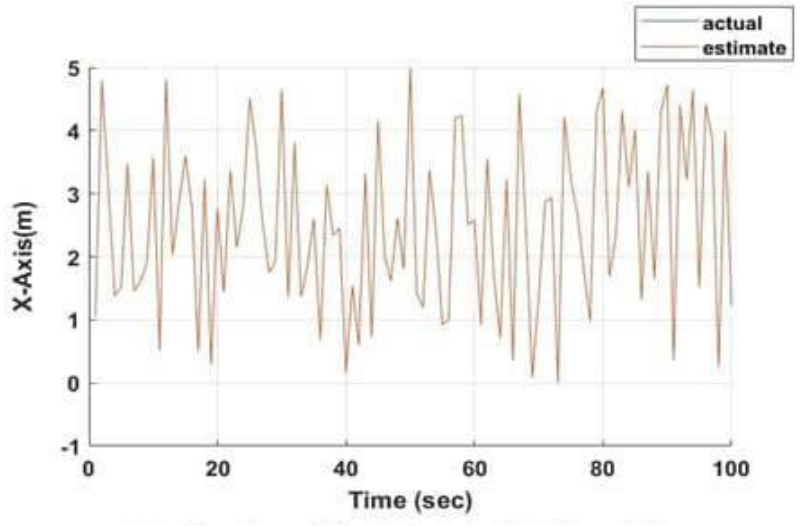

The Position of The X-Axis for The Tested Data

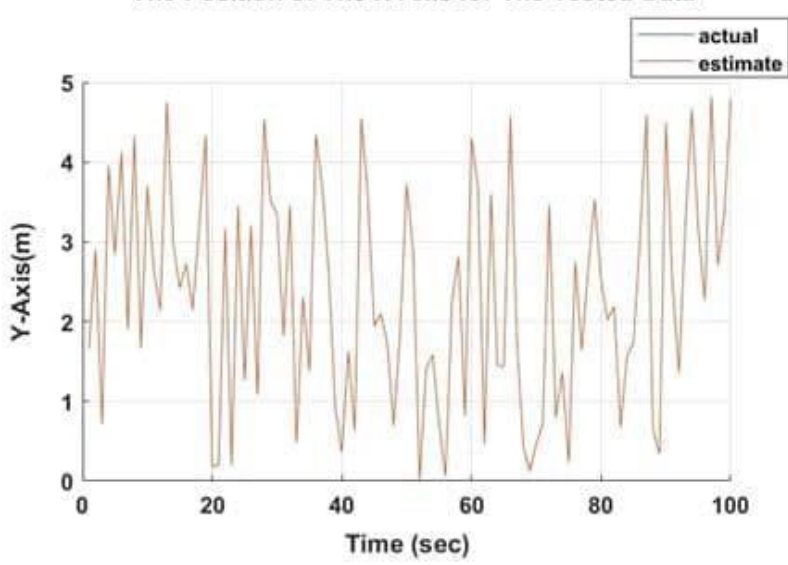

The Position of The Y-Axis for The Tested Data

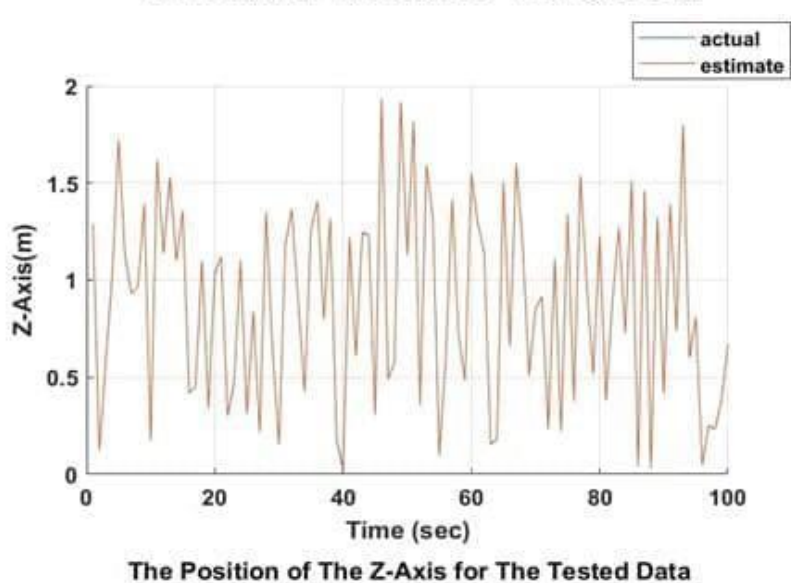

Figure. 18 The actual users location and the estimated users location in $\mathrm{x}-\mathrm{y}$ and $\mathrm{z}$-axis using DNN for testing the destines data

validity of our work was proven in the first stage, by following the triangulation method to simulate the data without noise to be explicit and real results and to check their validity so that we can follow them in the second stage. The RSS-Triangulation method was used to simulate the user's location data $(90,000$ user locations) and in the presence of noise, where the RSS was adopted within the triangulation method to reduce the error at the user's location, so the

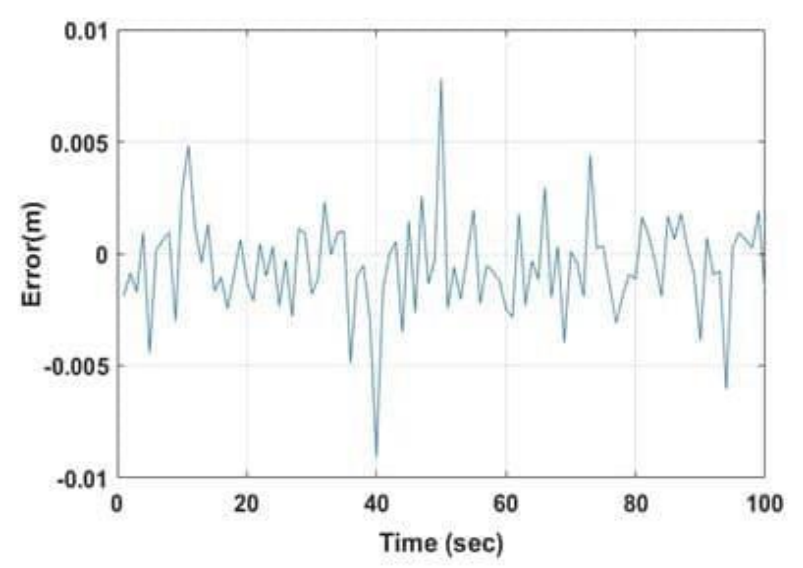

Error of The Position in The X-Axis for Tested Data

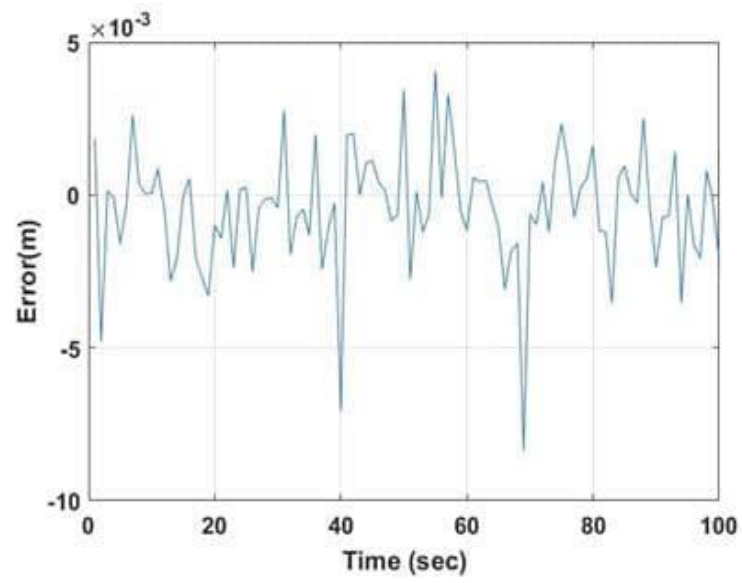

Error of The Position in The Y-Axis for Tested Data

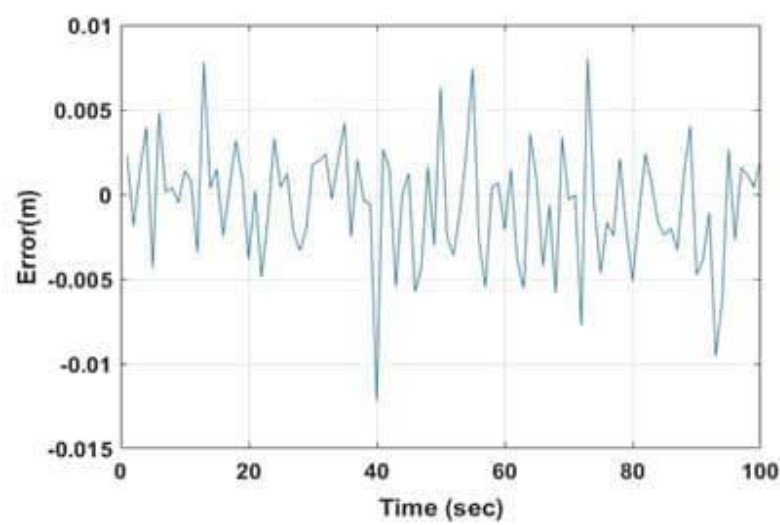

Error of The Position in The Z-Axis for Tested Data

Figure. 19 Error ratios in the $x-y-z$ axis using DNN for testing the destines data

average error in the $\mathrm{X}$ - axis $2.05612 \times 10^{-3} \mathrm{~cm}, \mathrm{Y}$ axis $4.56249 \times 10^{-3} \mathrm{~cm}$ and Z-axis $5.10474 \times$ $10^{-1} \mathrm{~cm}$ and we took advantage of the RSS to calculate the light power received by the user and the angle of light for the LEDs. The simulation was based on the RSS-triangulation method data within the deep learning algorithm, where it achieved high accuracy on the site compared to the latest work within the localization of Li-Fi. The highest error was 
Table 11. Comparison between the performance of the proposed $\mathrm{Li}-\mathrm{Fi}$ indoor localization and the performance of the Li$\mathrm{Fi}$ indoor localization in previous works

\begin{tabular}{|c|c|c|c|c|c|c|c|c|}
\hline Ref. & $\begin{array}{c}\text { Signal } \\
\text { properties }\end{array}$ & IPS method type & $\begin{array}{c}\text { positioning } \\
\text { algorithm }\end{array}$ & $\begin{array}{c}\text { Average } \\
\text { distance } \\
\text { error }\end{array}$ & $\begin{array}{c}\text { Average } \\
\text { positioning } \\
\text { time }\end{array}$ & \multicolumn{3}{|c|}{$\begin{array}{c}\text { positioning } \\
\text { accuracy }\end{array}$} \\
\hline [11] & RSS & Fingerprinting & ANN & $0.4 \mathrm{~mm}$ & & \multicolumn{3}{|c|}{$2 \mathrm{~m}$} \\
\hline [13] & $\begin{array}{l}\text { RSS and } \\
\text { PDOA }\end{array}$ & Triangulation & ANN & & & \multicolumn{3}{|c|}{$12 \mathrm{~cm}$} \\
\hline [15] & RSS & Triangulation & DNN & & & \multicolumn{3}{|c|}{$11.93 \mathrm{~cm}$} \\
\hline [17] & RSS & Fingerprinting & DNN & & $18 \mathrm{~ms}$ & \multicolumn{3}{|c|}{$14.55 \mathrm{~cm}$} \\
\hline \multirow{3}{*}{$\begin{array}{l}\text { Proposed } \\
\text { System }\end{array}$} & \multirow[b]{2}{*}{ RSS } & \multirow[b]{2}{*}{ Triangulation } & \multirow[b]{2}{*}{ DNN } & LED 1 & \multirow[b]{2}{*}{$7 s$} & $\mathrm{X}$ & $\mathrm{Y}$ & $\mathrm{Z}$ \\
\hline & & & & $\begin{array}{c}1.02489 \times \\
10^{-2} \mathrm{~cm}\end{array}$ & & $\begin{array}{c}2 \\
\mathrm{~cm}\end{array}$ & $\begin{array}{c}2 \\
\mathrm{~cm}\end{array}$ & $\begin{array}{c}4 \\
\mathrm{~cm}\end{array}$ \\
\hline & & & & $\begin{array}{c}\text { LED } 2 \\
1.02003 \times \\
10^{-2} \mathrm{~cm} \\
\text { LED } 3 \\
1.02125 \times \\
10^{-2} \mathrm{~cm} \\
\text { LED } 4 \\
1.02408 \times \\
10^{-2} \mathrm{~cm}\end{array}$ & & & & \\
\hline
\end{tabular}

on the $\mathrm{X}$-axis $2.51535 \mathrm{~cm}, \mathrm{Y}$-axis $2.25903 \mathrm{~cm}$, and $\mathrm{Z}$-axis $4.22898 \mathrm{~cm}$. In conclusion, our proposed work is a competitive option among the most recent previous research and it should be noted that the potential of using deep learning can go beyond what this work has revealed.

\section{Conflicts of interest}

The authors declare no conflict of interest.

\section{Author contributions}

The paper conceptualization, methodology, software, validation, formal analysis, investigation, resources, data curation, writing - original draft preparation, writing-review, and editing, visualization, have been done by 1 st author. The supervision and project administration has been done by 2 nd author.

Through the derivations for the triangulation equation, the coordinate of the user's location can be found by Eq. (7).

\section{References}

[1] W. Ayara, M. Usikalu, M. Akinyemi, T. Adagunodo, and K. Oyeyemi, "Review on Li-
Fi: an advancement in wireless network communication with the application of solar power", IOP Conference Series: Earth and Environmental Science, p. 012016, 2018.

[2] X. Guan, Q. Yang, Y. Hong, and C.Chan, "Nonorthogonal multiple access with phase predistortion in visible light communication", Optics Express, Vol. 24, No. 22, pp. 2581625823, 2016.

[3] M. Soltani, X. Wu, M. Safari, and H. Haas, "Bidirectional user throughput maximization based on feedback reduction in Li-Fi networks", IEEE Transactions on Communications, Vol. 66, No. 7, pp. 3172-3186, 2018.

[4] S. Wu, H. Wang, and C. Youn, "Visible light communications for $5 \mathrm{G}$ wireless networking systems: from fixed to mobile communications", IEEE Network Vol. 28, No. 6, pp. 41-45, 2014.

[5] K. Salman and E. Hamza, "Visible Light Fidelity Technology: Survey", Iraqi Journal of Computers, Communication, Control \& Systems Engineering, Vol. 21, No. 2, p. 1, 2021.

[6] M. Soltani, A. Purwita, Z. Zeng, H. Haas, and M. Safari, "Modeling the random orientation of mobile devices: Measurement, analysis and Li$\mathrm{Fi}$ use case", IEEE Transactions on Communications, Vol. 67, No. 3, pp. 2157-2172, 
2018.

[7] M. Alimadadi, A. Mohammadi, and M. Soltani "Throughput analysis of Ad-Hoc networks with a directional antenna at $60 \mathrm{GHz}$ ", Journal of Electromagnetic Waves and Applications, Vol. 28, No. 2, pp. 228-241, 2014.

[8] Y. Cai, W. Guan, Y. Wu, C. Xie, Y. Chen, and L. Fang, "Indoor high precision threedimensional positioning system based on visible light communication using particle swarm optimization", IEEE Photonics, Vol. 9, No. 6, pp. 1-20, 2017.

[9] Z. Bingcheng, C. Julian, W. Yongjin, Y. Jun, and W. Jinyuan, "Three-dimensional VLC positioning based on angle difference of arrival with an arbitrary tilting angle of a receiver", IEEE Journal on Selected Areas in Communications, Vol. 36, No. 1, pp. 8-22, 2017.

[10] C. Hao, C. Weipeng, L. Simin, and W. Yuxiang "Indoor high precision three-dimensional positioning system based on visible light communication using modified genetic algorithm", Optics Communications, Vol. 413, pp. 103-120, 2018.

[11] I. González, D. Rodríguez, B. Carlos, C. Bosch, and M. Suárez "Discrete indoor threedimensional localization system based on neural networks using visible light communication", Sensors Journal, Vol. 18, No. 4, pp. 10-40, 2018.

[12] M. Saadi, Z. Saeed, T. Ahmad, M. K. Saleem, and L.Wuttisittikulkij "Visible light-based indoor localization using k-means clustering and linear regression", Transactions on Emerging Telecommunications Technologies, Vol. 30, No. 2, pp. 34-80, 2019.

[13] S. Zhang, P. Du, C. Chen, W. Zhong, and A. Alphones, "Robust 3D indoor VLP system based on ANN using hybrid RSS/PDOA", IEEE Access, Vol. 7, pp. 47769-47780, 2019.

[14] Y. Chen, W. Guan, J. Li, and H. J. I. A. Song, "Indoor real-time 3-D visible light positioning system using fingerprinting and extreme learning machine", IEEE Access, Vol. 8, pp. 13875-13886, 2019.

[15] P. Du, S. Zhang, C. Chen, H. Yang, W. Zhong, R. Zhang, A. Alphones, and Y. Yang "Experimental demonstration of 3D visible light positioning using received signal strength with low-complexity trilateration assisted by deep learning technique", IEEE Access, Vol. 7, pp. 93986-93997, 2019.

[16] Y. Chen, H. Zheng, H. Liu, Z. Han, and Z. Ren, "Indoor High Precision Three-Dimensional Positioning System Based on Visible Light Communication Using Improved Hybrid Bat
Algorithm", IEEE Photonics J., Vol. 12, No. 5, pp. 1-13, 2020.

[17] M. Arfaoui, M. Soltani, I. Tavakkolnia, A. Ghrayeb, C. Assi, M. Safari, and H. Haas "Invoking deep learning for joint estimation of indoor LiFi user position and orientation", IEEE Journal on Selected Areas in Communications, 2021.

[18] L. Tabti, S. Kahlouche, B. Benadda, and B. Beldjilali, "Improvement of single-frequency GPS positioning performance based on EGNOS corrections in Algeria", The Journal of Navigation, Vol. 73, No. 4, pp. 846-860, 2020.

[19] A. Saba, K. Ekhlas, N. Qiang, and A. Alagan, "Industrial internet of things driven by SDN platform for smart grid resiliency", IEEE Internet of Things Journal, Vol. 6, No. 1, pp. 267-277, 2017.

[20] K. Nonalinsavath, L. Nugroho, Widyawan, K. Hamamoto, and S. Kanthavong, "An Integrated System for the Seamless Localization and Specification of a Position Based on an IndoorOutdoor Conditions in Ubiquitous Computing Environments", International Journal of Intelligent Engineering and Systems, Vol. 13, No. 5, 2020.

[21] K. Nonalinsavath, L. Nugroho, W. Widyawan, and K. Hamamoto, "Integration of Indoor Localization System using Wi-Fi Fingerprint, Bluetooth Low Energy Beacon and Pedometer Based on Android Application Platform", International Journal of Intelligent Engineering and Systems, Vol. 13, No. 4, pp. 171-181, 2020.

[22] Y. Zhuang, L. Hua, L. Qi, J. Yang, and P. Ca, "A survey of positioning systems using visible LED lights", IEEE Communications Surveys \& Tutorials, Vol. 20, No. 3, pp. 1963-1988 2018.

[23] J. Luo, L. Fan, and H. Li, "Indoor positioning systems based on visible light communication: State of the art", IEEE Communications Surveys \& Tutorials, Vol. 19, No. 4, pp. 2871-2893, 2017.

[24] N. Shahad and K. Ekhlas, "Path loss Optimization in WIMAX Network using Genetic Algorithm", Iraqi Journal of Computers, Communication, Control \& Systems Engineering, Vol. 20, No. 1, 2020.

[25] S. Princy, and G. Rajesh, "A Review On Visible Light Communication (VLC)", I-Manager's Journal on Communication Engineering and Systems, Vol. 8, No. 4, pp. 27-32, 2019.

[26] H. Tran and C. Ha, "Fingerprint-based indoor positioning system using visible light communication - a novel method for multipath reflections", Electronics, Vol. 8, No. 1, p. 63, 
2019.

[27] Z. Farid, R. Nordin, and M. Ismail, "Recent Advances in Wireless Indoor Localization Techniques and System", Journal of Computer Networks and Communications, Article ID.185138, p. 12, 2013

[28] K. Ekhlas and H. Russul, "Performance Analysis of IEEE 802.15.4 Transceiver System under Adaptive White Gaussian Channel", International Journal of Electrical \& Computer Engineering, Vol. 8, No. 6, pp. 2088-8708, 2018.

[29] E. Hamza and H. A. Asady, "Indoor Localization System Using Wireless Sensor Network", Iraqi Journal of Computers, Communications, Control \& Systems Engineering (IJCCCE), Vol. 18, No. 1, pp. 1811-9212, 2018.

[30] H. Hamid, E. Kadhum, W. Ismail, and M. Singh, "Analyze BER performance of wireless FSK system", Microwave and RF, Vol. 48, No.11, p. 80, 2009.

[31] Y. Eroglu, I. Guvenc, N. Pala, and M. Yuksel, "AOA-based localization and tracking in multielement VLC systems", In: Proc. of 2015 IEEE 16th Annual Wireless And Microwave Technology Conference (WAMICON), pp. 1520-1591, 2015.

[32] A. Naeem, N. Hassan, M. Pasha, C. Yuen, and A. Sikora, "Performance analysis of TDOAbased indoor positioning systems using visible LED lights", In: Proc. of 2018 IEEE 4th International Symposium on Wireless Systems Within the International Conferences on Intelligent Data Acquisition and Advanced Computing Systems (IDAACS-SWS), pp. 103107, 2018.

[33] T. Do and M. Yoo, "TDOA-based indoor positioning using visible light", Photon Netw Commun, Vol. 27, No. 2, pp. 80-88, 2014.

[34] Y. Wu, C. Chow, Y. Liu, Y. Lin, C. Hong, D. Lin, S. Song, and C. Yeh, "Received-signalstrength (RSS) based 3D visible-lightpositioning (VLP) system using kernel ridge regression machine learning algorithm with sigmoid function data preprocessing method", IEEE Access, Vol. 8, pp. 214269-214281, 2020.

[35] Y. Almadani, "Visible Light Positioning using Received Signal Strength for Industrial Environments", Ph. D. Thesis in Manchester Metropolitan University, 2020.

[36] S. Büyükçorak and G. K. Kurt, "A Bayesian perspective on RSS based localization for visible light communication with heterogeneous networks extension", IEEE Access, Vol. 5, pp. 17487-17500, 2017.
[37] C. Gin, D. Shea, S. Brunton, and J. Kutz, "Deepgreen: Deep learning of green's functions for nonlinear boundary value problems", ScientificRreports, Vol. 11, No. 1, pp. 1-14, 2021.

[38] B.Ding, H. Qian, and J. Zhou, "Activation functions and their characteristics in deep neural networks", In: Proc. of 2018 Chinese Control and Decision Conference (CCDC), pp. 18361841, 2018.

[39] A. Lydia and S. Francis, "Adagrad-an optimizer for stochastic gradient descent", International Journal of Information and Computing Science, Vol. 6, No. 5, pp. 09721347, 2019.

[40] A. Kumar, S. Sarkar, and C. Pradhan, "Malaria disease detection using cnn technique with sgd, rmsprop and adam optimizers", Deep Learning Techniques for Biomedical and Health Informatics, pp. 211-230, 2020.

[41] D. Kingma and J. Ba, "Adam: A method for stochastic optimization", Conference Paper At ICLR 2015, pp.1412.6980, 2014. 